\title{
LA EJECUCIÓN DE LAS SENTENCIAS DEL TEDH RELATIVAS A LA FEDERACIÓN DE RUSIA Y A TURQUÍA: ¿̇HAN FRACASADO LAS REFORMAS DEL PROTOCOLO 14?
}

\author{
JAUME FERRER LLORET ${ }^{1}$ \\ Universidad de Alicante \\ jaume.ferrer@ua.es
}

\section{Resumen}

La acumulación de miles de sentencias del Tribunal Europeo de Derechos $\mathrm{Hu}$ manos (TEDH) pendientes de ejecutar y, algo más en concreto, de cientos de sentencias que certifican la vulneración de derechos humanos inderogables a cargo de la Federación de Rusia y Turquía constituye uno de los principales déficits del sistema

1 Catedrático de Derecho Internacional Público y Relaciones Internacionales de la Universidad de Alicante. Titular de la Cátedra Jean Monnet «European Neighbourhood Policy: EU Values and Global Challenges». El presente trabajo se enmarca en el proyecto de investigación coordinado, concedido por el Ministerio de Economía y Competitividad, «La Unión Europea ante los Estados fracasados de su vecindario: retos y respuestas desde el Derecho Internacional (II)» (DER2015-63498-C2-2-P [MINE$\mathrm{CO} / \mathrm{FEDER}]$ ). El autor agradece las observaciones que los dos evaluadores llevaron a cabo sobre este trabajo. 
de protección establecido por el Convenio de Roma. Para tratar de dar respuesta a esta lamentable situación, en su día se introdujeron algunas reformas mediante la adopción del Protocolo 14; en particular la posibilidad de que el Comité de Ministros (CM), el órgano encargado de la supervisión de la ejecución de las sentencias, pueda interponer un recurso por incumplimiento ante el TEDH. Pero el estudio de la práctica relativa a estos dos Estados, pone de manifiesto que el CM viene protagonizando una actuación excesivamente lenta y se podría decir que bajo mínimos. De hecho, un buen número de sentencias del TEDH no se ejecutan, sin ninguna reacción por parte del CM, excepto por lo que se refiere a la publicación de algunas resoluciones provisionales.

\title{
Palabras clave
}

Tribunal Europeo de Derechos Humanos; Comité de Ministros; ejecución de sentencias; derechos humanos inderogables; Federación de Rusia; Turquía; Protocolo 14; recurso por incumplimiento.

\section{THE EXECUTION OF THE ECHR'S JUDGMENTS REGARDING THE RUSSIAN FEDERATION AND TURKEY: HAVE THE REFORMS OF THE PROTOCOL 14 FAILED?}

\begin{abstract}
The accumulation of thousands of judgments of the European Court of Human Rights (ECHR) pending execution and, more specifically, hundreds of judgments certifying the violation of non-derogable human rights by the Russian Federation and Turkey, is one of the most serious deficits of the protection system established by the Rome Convention. At one point and with a view to responding to this regrettable situation, some reforms were introduced through the adoption of Protocol 14; in particular, the possibility that the Committee of Ministers (CM), the body in charge of supervising the execution of judgments, may bring infringement proceedings before the ECHR. But the study of the practice relative to these two States shows that the CM has been acting excessively slowly and one could say that at low ebb. In fact, a good number of judgments of the ECHR are not executed, without any reaction from the CM, except for the publication of some Interim Resolutions.
\end{abstract}

\section{Keywords}

European Court of Human Rights; Committee of Ministers; Execution of Judgments; Non-derogable Human Rights; Russian Federation; Turkey; Protocol 14; Infringement Proceedings. 


\section{L'EXECUTION DES ARRÊTS DE LA CEDH RELATIVES À LA FÉDÉRATION DE RUSSIE ET À LA TURQUIE: ìLES REFORMES DU PROTOCOLÉ 14 ONT-ELLES ECHOUÉ?}

Résumé

L'accumulation de milliers d'arrêts de la Cour européenne des droits de l'homme $(\mathrm{CEDH})$ en attente d'exécution et, plus particulièrement, des centaines d'arrêts certifiant la violation de droits de l'homme indérogeables par la Fédération de Russie et la Turquie, est l'un des principaux déficits du système de protection établi pour la Convention de Rome. Afin d'essayer de répondre à cette situation lamentable, certaines réformes ont été introduites par l'adoption du Protocole 14; en particulier, la possibilité que le Comité des Ministres (CM), l'organe chargé de contrôler l'exécution d'arrêts, puisse déposer un recours en manquement devant la CEDH. Mais l'étude de la pratique relative à ces deux États, montre que le CM conduit une action trop lente et on pourrait dire que plus bas. En effet, un bon nombre d'arrêts de la $\mathrm{CEDH}$ ne sont pas exécutés, sans aucune réaction du CM, à l'exception de la publication de certaines résolutions intérimaires.

\section{Mots clés}

Cour européenne des droits de l'homme; Comité des Ministres; Exécution d'arrêts; Droits de l'homme non susceptibles de dérogation; Fédération de Russie; Turquie; Protocole 14; recours en manquement. 


\section{SUMARIO}

I. INTRODUCCIÓN. II. LA SUPERVISIÓN DE LA EJECUCIÓN DE LAS SENTENCIAS DEL TEDH TRAS LA REFORMA DEL PROTOCOLO 14: 1. El CEDH encarga al Comité de Ministros la supervisión de la ejecución de las sentencias del TEDH. 2. Un procedimiento de supervisión basado en la colaboración de las autoridades del Estado. III. LA PRÁCTICA QUE CONCIERNE A LA FEDERACIÓN DE RUSIA. IV. LA PRÁCTICA REFERIDA A TURQUÍA. V. SOBERANIIA DE LOS ESTADOS Y DERECHOS HUMANOS EN EL ÁMBITO REGIONAL EUROPEO: 1. Valoración de la práctica estudiada. 2. Algunas propuestas de lege ferenda. VI. CONCLUSIONES. BIBLOGRAFía.

\section{INTRODUCCIÓN}

El sistema de protección regional de derechos humanos, establecido por el Convenio Europeo para la Protección de los Derechos Humanos y de las Libertades Fundamentales de 4 de noviembre de 1950 (CEDH $)^{2}$, se encuentra en una situación de crisis perenne, sobre todo como consecuencia de la inmensa carga de trabajo a la que tiene que hacer frente. Este diagnóstico es fácilmente demostrable: a 31 de mayo de 2018 se contabilizan un total de 55200 demandas pendientes de contestar por parte del TEDH; con Rumanía (9500), Rusia (8950), Ucrania (7300), Turquía (6400) e Italia (4750) en los primeros lugares por lo que se refiere al orden de prelación de Estados que más demandas acumulan ${ }^{3}$. Para tratar de dar alguna respuesta, como últimas reformas al $\mathrm{CEDH}$ se han adoptado los protocolos 15 y 16 . Aunque resulta difícil prever si con estas reformas se alcanzarán plenamente los objetivos para los que han sido aprobadas, se puede mantener una buena dosis de escepticismo al respecto ${ }^{4}$.

2 BOE de 10 de octubre de 1979.

3 Según los datos que se ofrecen en la página web del TEDH: https://bit.ly/2Mv5Kyb. Todas las direcciones de internet que se citan han sido consultadas por última vez a 30 de junio de 2018.

4 Con el Protocolo 15, adoptado el 24 de junio de 2013, entre otras modificaciones se insiste en el principio de subsidiariedad y en el margen de apreciación de que disfrutan los Estados en la aplicación del Convenio, y se reduce el plazo para presentar una 
A causa de esta impresionante sobrecarga de trabajo y la falta de medios personales y financieros para poder hacerle frente, el TEDH está tardando por regla general más de media década en dictar sentencia desde que se presenta la demanda en Estrasburgo, como se podrá comprobar en concreto por lo que respecta a las sentencias citadas a lo largo de este trabajo. Esta dilación en el procedimiento judicial que se desarrolla ante el TEDH podría ser considerada como contraria a lo dispuesto en el propio art. 6.1 del CEDH, en el que se prevé el derecho de acceso a los tribunales en un plazo razonable. Además, una vez se haya dictado sentencia, en ocasiones su ejecución se puede retrasar considerablemente, e incluso puede ocurrir que la inejecución se prolongue durante años y años sin perspectiva de solución, como se pone de manifiesto en buena parte de las sentencias que corresponde ejecutar a la Federación de Rusia y a Turquía (epígrafes III y IV).

Por lo que se refiere a los datos globales de los dos últimos años, según la información que proporciona el órgano encargado de supervisar la ejecución de las sentencias, el Comité de Ministros, se aprecia la siguiente evolución: a 31 de diciembre de 2016 se contabilizaban 9941 casos pendientes de ejecutar. De los cuales, 1493 eran calificados de leading cases ${ }^{5}$, y el resto, 8448, de repetitive cases $^{6}$. Entre los Estados que en esa fecha más casos pendientes de ejecutar acumulaban dentro del subprocedimiento reforzado ${ }^{7}$ se encontraban

demanda ante el TEDH de 6 a 4 meses desde que se agotaron los recursos internos. Está previsto que entre en vigor cuando sea ratificado por los 47 Estados partes en el CEDH y a fecha de hoy faltan cuatro: Bosnia Herzegovina, España, Grecia e Italia. Con el Protocolo 16, adoptado el 2 de octubre de 2013, se prevé que las más altas jurisdicciones de los Estados partes puedan solicitar opiniones consultivas al TEDH sobre cuestiones de principio relativas a la interpretación o la aplicación de los derechos y libertades reconocidos en el CEDH. Ha sido ratificado por diez Estados —entre los que no se encuentra España_-, el último de ellos Francia, por lo que está previsto que entre en vigor para los Estados que lo han ratificado el 1 de agosto de 2018: https:// bit.ly/2O56bEV.

5 Según el CM, se entiende por leading case, "case with has been identified as revealing new structural and/or systemic problems, either by the Court directly in its judgment, or by the Committee of Ministers in the course of its supervision of execution. Such a case requires the adoption of new general measures to prevent similar violations in the future» (Comité de Ministros, 2016: 43).

6 Se trata de un «case relating to a structural and/or general problem already raised before the Committee in the context of one or several leading cases; repetitive cases are usually grouped together with the leading case» (Comité de Ministros, 2016: 43).

7 En el epígrafe II.2 se dará cuenta de los dos subprocedimientos que aplica el CM, el reforzado y el estándar. 
la Federación de Rusia — 17 \%—, Ucrania — 16 \%- y Turquía — $11 \%$ (Comité de Ministros, 2016: 64). En 2016 el TEDH había transmitido al CM un total de 1352 nuevos casos y se cerraron 2066 (ibid.: 46, 48 y 53).

Un año después los datos parecen indicar un notable avance por lo que se refiere al aumento del número de casos cerrados y la aminoración del número de casos pendientes de ejecutar. A 31 de diciembre de 2017 se contabilizan 7584 casos pendientes de ejecutar: 1379 leading cases y 6205 repetitive cases. De nuevo, con los mismos tres Estados en los primeros lugares dentro del subprocedimiento reforzado: la Federación de Rusia - 18,2 \%-, Ucrania —16,9 \%- y Turquía - 11,5 \%- (Comité de Ministros, 2017: 75). En 2017 el TEDH había transmitido 1333 nuevos casos y se cerraron 3691: 311 leading cases y 3380 repetitive cases (ibid.: 2017: 57 y 67-68). Lo que constituye la cifra más alta de casos cerrados en un solo año en la historia de la labor del CM; y supone una clara tendencia hacia la disminución del número de casos pendientes de ejecutar, cuyo número ha pasado de 11099 a finales de 2012, a 7584 a finales de 2017 (ibid.: 2017: 61).

Aunque, como se demostrará en los epígrafes III y IV, estos datos globales, que en principio pueden considerarse positivos porque reflejan un balance favorable, no afectan sustancialmente al número de sentencias pendientes de ejecución en los supuestos de la Federación de Rusia y de Turquía. Sobre todo por lo que respecta a la ejecución de las que se ocupan de la vulneración de los derechos humanos considerados inderogables en cualquier circunstancia por el art. 15 del CEDH, en lo que a continuación se insistirá. De hecho, el apreciable aumento del número de casos cerrados en 2017 en buena medida es debido a que en esa anualidad se han cerrado 1700 casos relativos a dilaciones indebidas en el procedimiento judicial ante los tribunales italianos, así como varios cientos de casos referidos a la situación en las cárceles de Hungría (250) y Polonia (100) (Comité de Ministros, 2017: 14).

Por tanto, la acumulación de miles de sentencias pendientes de ejecutar que se arrastra durante los últimos años, y algo más en concreto de cientos de casos referidos a la protección de derechos humanos inderogables que conciernen a la Federación de Rusia y a Turquía (III y IV), constituye uno de los principales déficits del sistema de protección de los derechos humanos establecido por el CEDH. Para tratar de dar solución, en su momento se introdujeron algunas reformas en el CEDH mediante la adopción del Protocolo 14, el 13 de mayo de 2004. Este protocolo no entró en vigor hasta el 1 de junio de 2010, debido precisamente al retraso de la Federación de Rusia en ratificarlo 
(el 18 de febrero de 2010) ${ }^{8}$. Se cumplen, por tanto, ocho años desde su entrada en vigor. Los datos que se acaban de comentar pueden causar la impresión de que las reformas del Protocolo 14 - que serán objeto de análisis en el siguiente epígrafe II-, aunque evidentemente no han resuelto el problema, al menos han servido para paliarlo, visto que en los últimos años se ejecutan más sentencias que nuevos casos pendientes de ejecución se le transmiten al CM.

Pero esta valoración muy moderadamente positiva se debe poner en entredicho por lo que se refiere a las sentencias pendientes de ejecutar relativas a la Federación de Rusia y a Turquía (III y IV). En efecto, dentro de la limitada extensión de este artículo, se ha optado por centrar el estudio de la práctica en estos dos Estados, que asumen un indudable protagonismo en esta lamentable historia de falta de cumplimiento de las sentencias dictadas por el TEDH. Desde un punto de vista cuantitativo, porque se sitúan entre los primeros de la lista en número de sentencias pendientes de ejecutar, como se acaba de citar. Y sobre todo, desde una óptica cualitativa, porque buena parte de las sentencias pendientes de ejecutar que conciernen a estos dos Estados declaran la vulneración de los arts. 2 - derecho a la vida- y 3 - prohibición de la tortura-, y también art. 13 - derecho a un recurso efectivo- con relación a los anteriores. Derechos los dos primeros que según el art. 15 del CEDH deben ser considerados como inderogables en cualquier circunstancia, junto con los reconocidos en los arts. 4.1 - prohibición de esclavitud- - 7 - no hay pena sin ley-. En última instancia, como se volverá a insistir en el epígrafe $\mathrm{V}$, en la problemática que presenta la falta de ejecución de las sentencias del TEDH en los supuestos de la Federación de Rusia y de Turquía, lo que está en juego es la capacidad del sistema de protección establecido por el CEDH para poder hacer frente a situaciones de vulneración grave y masiva de los derechos humanos. Ya se puede adelantar que el estudio de la práctica demuestra que el resultado que en este ámbito ofrece la aplicación del sistema de protección europeo no es en absoluto satisfactorio, ni mucho menos, como se concluirá al final de este trabajo (VI).

8 Todo indica que las autoridades rusas pospusieron la ratificación del Protocolo 14 durante varios años como modo de protesta ante su descontento con el elevado número de sentencias dictadas por el TEDH en su contra, y más en particular por la admisión en Estrasburgo de la demanda presentada en el caso OAO Neftyanaya kompaniya YUKOS v. Russia, app. 14902/04, en el que estaba en juego una elevada suma de dinero. La postura obstruccionista de la Federación de Rusia provocó que el resto de Estados adoptaran el llamado Protocolo 14bis, el 27 de mayo de 2009, con el objetivo de que los Estados que lo ratificaran - solamente tres - pudieran aplicar una parte de las reformas previstas en el Protocolo 14 a la espera de la entrada en vigor de este último (Bowring, 2010: 605-613). 


\section{LA SUPERVISIÓN DE LA EJECUCIÓN DE LAS SENTENCIAS DEL TEDH TRAS LA REFORMA DEL PROTOCOLO 14}

\section{EL CEDH ENCARGA AL COMITÉ DE MINISTROS LA SUPERVISIÓN DE LA EJECUCIÓN DE LAS SENTENCIAS DEL TEDH}

Con carácter general y de forma lacónica, el art. 46.2 del CEDH preceptúa que el TEDH debe transmitir al CM las sentencias definitivas, para que vele por su ejecución. Pero este precepto no ofrece ninguna precisión sobre el procedimiento y las medidas a aplicar para que el CM desarrolle esta función. Por tanto, la escueta regulación que ofrece el CEDH de entrada permite un amplio margen de discrecionalidad por parte del CM, que como es obvio es un órgano intergubernamental. De este modo, los Estados partes en el CEDH han decidido que la supervisión de la ejecución de las sentencias del TEDH sea automática y colectiva: los propios Estados partes representados en el CM se van a supervisar entre sí. Se trata, en definitiva, de una supervisión mutua o recíproca que se lleva a cabo en el marco de un órgano de naturaleza política (Fortas, 2015: 50 y 61; Saavedra y Cano, 2017: 246).

Por lo que se refiere a la ejecución de las sentencias del TEDH, el Protocolo 14 introdujo como principales reformas la posibilidad de que el CM interponga los recursos de interpretación y de incumplimiento. El art. 46.3 del CEDH prevé que el CM puede presentar ante el TEDH un recurso de interpretación, en el supuesto de que considere que «la supervisión de la ejecución de una sentencia definitiva resulta obstaculizada por un problema de interpretación de dicha sentencia con objeto de que éste se pronuncie sobre dicho problema de interpretación». Para ello será necesario que se alcance una mayoría de dos tercios de los votos de los representantes que tengan derecho a formar parte del CM.

La misma mayoría se exige para que el CM presente un recurso por incumplimiento y por tanto remita al TEDH la cuestión de si un Estado parte ha incumplido la obligación de acatar las sentencias definitivas del Tribunal, si considera que dicho Estado se niega a acatar una sentencia definitiva sobre un asunto en que es parte y tras notificarlo formalmente a ese Estado (art. 46.4). Le corresponde a la Gran Sala pronunciarse sobre los recursos por incumplimiento que le plantee el CM [art. 31.b)]. Si esta concluye que efectivamente el Estado ha incumplido su obligación de acatar las sentencias definitivas, deberá remitir el asunto al CM para que examine las medidas que sea preciso adoptar (art. 46.5). Pero no se menciona qué tipo de medidas puede adoptar el CM a este respecto. 
Entre otras posibles actuaciones, no se incluye una remisión a lo dispuesto en el art. 8 del Estatuto del Consejo de Europa ${ }^{9}$, en el que se prevé que el CM puede suspender el derecho de representación del Estado miembro que infrinja gravemente lo dispuesto en su art. 3 (en el que se afirma el principio del respeto de los derechos humanos de las personas que se hallen bajo la jurisdicción de cualquier Estado parte), pudiendo invitarle a retirarse de esta organización internacional según las condiciones previstas en el art. 7 de dicho estatuto. Y si el Estado hace caso omiso a la invitación del CM, este podrá decidir la expulsión del Estado en la fecha que determine ${ }^{10}$. La posibilidad de que un Estado miembro sea expulsado resulta coherente con el art. 4, en el que se exige como condición para ser miembro del Consejo de Europa que el Estado sea "capaz de cumplir las disposiciones del artículo 3, y que tenga voluntad de hacerlo». Hasta la fecha, el CM nunca ha decidido la suspensión o la expulsión de un Estado miembro, ni siquiera en supuestos como los de la Federación de Rusia o de Turquía, Estados que acumulan cientos de sentencias pendientes de ejecutar en las que se declara la vulneración de los arts. 2 y 3 del CEDH (III y IV). A pesar de que el propio órgano ha afirmado públicamente que aceptar el carácter obligatorio de las sentencias del TEDH es una condición para ser miembro del Consejo de Europa, no ha extraído ninguna consecuencia de ello a los efectos de la aplicación del citado art. 8 del Estatuto $^{11}$.

Ante la parquedad de las disposiciones del CEDH dedicadas a la ejecución de las sentencias del TEDH, el CM ha aprobado las «Rules for the execution of judgments and of terms of friendly settlements» (en adelante, Normas de Ejecución), con las que desarrolla el procedimiento aplicable en los poderes que se le encomiendan de supervisar la ejecución tanto de los arreglos amistosos como las sentencias definitivas del TEDH. Fueron aprobadas en su primera versión en la reunión del CM celebrada el 10 de mayo de 2006 y posteriormente han sido enmendadas en varias ocasiones, la última de ellas en la reunión de este órgano del 18 de enero de 2017. De hecho, las modificaciones y la aplicación en la práctica de las Normas de Ejecución han permitido

9 Hecho en Londres el 5 de mayo de 1949: BOE de 1 de marzo de 1978.

10 Según el art. 20 d) del Estatuto de Londres, las decisiones del CM relativas al art. 8, "[...] se adoptarán por mayoría de dos tercios de los votos emitidos y por la mayoría de los representantes con derecho a formar parte de aquél».

11 Por ejemplo, Interim Resolution CM/ResDH(2007)106 concerning the judgment of the European Court of Human Rights of 8 July 2004 (Grand Chamber) in the case of Ilaşcu and others against Moldova and the Russian Federation: "Reaffirming most firmly that the obligation to abide by the judgments of the Court is unconditional and is a requirement for membership of the Council of Europe». 
el desarrollo del procedimiento de supervisión de la ejecución de las sentencias del TEDH, a partir sobre todo de la Conferencia Interministerial celebrada en febrero de 2010 en Interlaken y también de las posteriores ${ }^{12}$, con el objetivo general, en palabras del CM, de que el procedimiento de supervisión sea «más efectivo y transparente» (Comité de Ministros, 2017: 247).

\section{UN PROCEDIMIENTO DE SUPERVISIÓN BASADO EN LA COLABORACIÓN DE LAS AUTORIDADES DEL ESTADO}

No obstante las previsiones del CEDH ya señaladas y de los citados arts. 3 y 8 del Estatuto de Londres, el éxito final del procedimiento de supervisión que viene aplicando el $\mathrm{CM}$ en los últimos años (incluidas sentencias que versan sobre situaciones de vulneración grave y masiva de los derechos humanos, a las que se hará referencia en los dos siguientes epígrafes en los supuestos de la Federación de Rusia y de Turquía) se basa fundamentalmente en la colaboración que presten las autoridades del Estado declarado infractor por el TEDH: en la práctica, el procedimiento se desarrolla con el objetivo primordial de ayudar al Estado sobre cómo debe llevar a cabo la ejecución de las sentencias, en su caso proponiéndole las medidas que debe aplicar con este fin. Naturaleza asistencial que se vehiculiza a través del diálogo permanente que se mantiene entre el Estado obligado a ejecutar la sentencia dictada en su contra por el TEDH, por una parte, y el CM y el órgano técnico que le asiste, el Servicio de Ejecución ${ }^{13}$, por otra. Tal diálogo se concreta formalmente a

12 Las Normas de Ejecución se pueden consultar en https://rm.coe.int/16806eebf0. Tras la adopción del Protocolo 14 se han sucedido las conferencias interministeriales de Interlaken (2010), Izmir (2011), Brighton (2012), Bruselas (2015) y Copenhague (2018), en las que se han debatido las reformas del sistema de protección establecido por el CEDH que deben llevarse a cabo para tratar de asegurar su efectivo funcionamiento ante la enorme carga de trabajo a la que tiene que hacer frente. Debate que hasta la fecha ha dado como resultado la adopción de los mencionados Protocolos 15 y 16. Además de aprobarse las correspondientes declaraciones en cada una de las conferencias citadas, referidas a diversos aspectos del funcionamiento del sistema. Como se explica en el último Informe del Comité Director de Derechos Humanos (Steering Committee for Human Rights, 2016: 27-28). Se trata de un órgano que actúa bajo la autoridad del CM y que está formado por expertos que representan a los 47 Estados partes en el CEDH; también pueden asistir a las reuniones expertos procedentes de la sociedad civil, en particular representantes de ONG. Véase: www.coe.int/Steering Committee for Human Rights.

13 Bajo la autoridad del director general al frente de la Dirección General Derechos Humanos y Estado de Derecho, el Servicio de Ejecución asume con carácter general las 
través de los planes y balances de acción presentados por el Estado, y las resoluciones provisionales y las resoluciones finales adoptadas por el Comité de Ministros (Salinas Alcega, 2015: 34 y ss.) ${ }^{14}$.

En la práctica se distinguen dos subprocedimientos: el reforzado (enhanced) y el estándar (Fortas, 2015: 327-338; Saavedra y Cano, 2017: 246249). Dentro del primero se incluyen: a) las sentencias que afectan a casos que requieren medidas individuales urgentes; b) las sentencias piloto; c) las sentencias en las que el TEDH y/o el CM identifican problemas estructurales y/o complejos, cuya ejecución requiere la adopción de medidas generales para prevenir violaciones similares en el futuro; y d) sentencias relativas a demandas interestatales. Las sentencias de los supuestos b) y d) son incluidas automáticamente dentro del subprocedimiento reforzado. Según explica el propio CM, «this procedure is intended to allow the Committee of Ministers to closely follow progress of the execution of a case, and to facilitate exchanges with the national authorities supporting execution» (Comité de Ministros, 2017: cita en 53 y 251-252).

Por exclusión, la supervisión de la ejecución del resto de sentencias se lleva a cabo en el marco del subprocedimiento estándar, que se basa en la obligación que recae sobre el Estado de asegurar la efectiva ejecución de las sentencias del TEH, de conformidad con el principio de subsidiariedad. Por tanto, la intervención del CM se limita a asegurar que se han presentado debidamente los planes de acción y a verificar que las medidas propuestas son apropiadas y se aplican en el tiempo previsto. En este segundo supuesto, el desarrollo del procedimiento es llevado a cabo sobre todo por el Servicio de Ejecución, que informa al CM del mismo y en su caso le podrá presentar propuestas de actuación si se requiere alguna intervención específica por su parte (Comité de Ministros, 2017: 56 y 251-253).

Se debe destacar, en esta dirección, que la enorme carga de trabajo a la que está sometido el CM en su labor de supervisión, con miles de sentencias pendientes de ejecutar, ha obligado a que el Servicio de Ejecución se convierta en

siguiente funciones: por una parte, asesorar y asistir al CM en su labor de supervisión de la ejecución de las sentencias del TEDH; por otra, también se encarga de ofrecer apoyo a los Estados partes en el cumplimiento de su obligación de ejecutar las sentencias. Véase: https://www.coe.int/en/web/execution/presentation-of-the-department.

14 Se debe añadir que en marzo de 2008 se creó el Fondo Fiduciario para los Derecho Humanos, con el objetivo de financiar diversas actividades de cooperación con los Estados miembros para prestarles asistencia en la aplicación del CEDH, y más en particular en la ejecución de las sentencias del TEDH. Tema sobre el que todos los años se suelen organizar algunos seminarios o jornadas en distintos Estados, como se puede consultar en https://www.coe.int/en/web/programmes/projects-funded. 
el gestor cotidiano en la aplicación del procedimiento, con lo que se aporta un enfoque o componente eminentemente técnico en su desarrollo. De hecho, por regla general el CM prácticamente se limita a avalar la gestión desarrollada por el Servicio de Ejecución. Aunque el órgano que formalmente asume la competencia es el CM, lo que explica que todos los asuntos se incluyan en el orden del día de las reuniones de derechos humanos de este último órgano, también los que estén sometidos al subprocedimiento estándar (Salinas Alcega, 2015: 30-31).

Conviene añadir que durante el desarrollo del procedimiento de supervisión, un caso puede ser transferido desde el subprocedimiento estándar al reforzado, y viceversa, según decida el CM. A 31 de diciembre de 2017, de los 7584 casos pendientes, 3379 estaban clasificados dentro del subprocedimiento estándar; 3849, dentro del reforzado, y 356 permanecían sin clasificar. Se debe reseñar también que en 2017 se cerraron 1177 casos dentro del estándar y 2514 dentro del reforzado (Comité de Ministros, 2017: 63 y 68). Asimismo, recientemente en un informe elaborado en el seno de la Asamblea Parlamentaria se ponía atención en el hecho de que casi la mitad de los casos incluidos dentro del subprocedimiento reforzado son relativos a vulneraciones de los arts. 2, 3 y 5 del CEDH (Asamblea Parlamentaria, 2018: 10); derechos humanos referidos a la protección de la vida, la integridad física y la libertad y seguridad personales, respectivamente.

Aunque no parece que esta distinción conlleve consecuencias muy apreciables para el Estado declarado infractor por el TEDH. En efecto, como ya se ha señalado, la aplicación de ambos subprocedimientos se basa en el diálogo permanente y la colaboración entre, por una parte, las autoridades del Estado que está obligado a ejecutar la sentencia y, por otra, el CM y el Servicio de Ejecución, como órgano técnico encargado de asesorarle y asistirle; con el objetivo final de que el Estado cumpla su obligación de ejecutar la sentencia y el CM dé por cerrado el procedimiento de supervisión. En este sentido, en un plazo de seis meses desde que la sentencia es definitiva, el Estado debe comunicar al CM las medidas que ha adoptado o piensa adoptar para ejecutarla (norma 6.1). En la práctica del procedimiento de supervisión se distingue entre el Plan de Acción, documento con el que el Estado da cuenta de las medidas que ha adoptado o que va a adoptar para ejecutar la sentencia del TEDH y prevé un calendario al respecto; y el Balance de Acción, con el que el Estado informa al CM de que ha aplicado todas las medidas necesarias para ejecutarla y/o las razones por las que no ha adoptado medidas adicionales (Fortas, 2015: 241 y ss.).

A la vista de la información que proporciona el Estado, el CM debe examinar tanto si el Estado ha pagado la satisfacción equitativa a la que estaba obligado en virtud de la sentencia del TEDH (art. 41 del CEDH); como si 
ha adoptado las medidas, ya sean individuales, dirigidas a asegurar que la violación del $\mathrm{CEDH}$ ha cesado y se ha restablecido la situación de la víctima a la que se encontraba antes de cometerse la vulneración de sus derechos; ya sean generales, dirigidas a prevenir que otras vulneraciones similares del CEDH se cometan en el futuro y a detener las que en su caso se estén cometiendo (norma 6.2; Comité de Ministros, 2016: 284-286 y Comité de Ministros, 2017: 247-250).

Se debe destacar la interacción que se puede desarrollar entre el TEDH y el CM a los efectos de la aplicación del art. 46.1 y 2 del CEDH. Ya que el Tribunal, por una parte, puede dictar una sentencia piloto con la que indique las medidas de carácter general, incluso legislativas, que debe adoptar el Estado para que se produzca el cese de las vulneraciones del CEDH y prevenir nuevas violaciones en el futuro ${ }^{15}$. Por otra, también puede dictar otras sentencias en las que asimismo determine medidas relevantes, de alcance particular o general, a

15 Previstas en el art. 61 del Reglamento del TEDH. En el supuesto de una sentencia piloto, el TEDH debe identificar los problemas estructurales o sistémicos que en un Estado impiden la correcta aplicación del CEDH y debe proponer las medidas que debe adoptar el Estado en su ordenamiento interno para corregir esta situación. Durante el procedimiento que permitirá dictar la sentencia piloto, el TEDH podrá aplazar la respuesta de todas las demandas similares que se hayan planteado, y la respuesta que dé el TEDH en su sentencia piloto podrá ser aplicada a tales demandas o incluso a otras demandas similares que puedan presentarse en el futuro. Pero si el Estado parte no cumple lo dispuesto en la sentencia piloto, el TEDH podrá examinar y dictar sentencia sobre todas las demandas similares que fueron aplazadas (Abrisketa Uriarte, 2013: 75 y ss.). Como ejemplo reciente, se puede citar la Sentencia de la Gran Sala de 12 de Octubre de 2017, Burmych and Others v. Ukraine (ECLI:CE:ECHR:2017:1012JUD004685213), con la que por una mayoría de diez contra siete, la Gran Sala decide que la inejecución de las sentencias internas de los tribunales de Ucrania supone una vulneración de los arts. 6.1 y 13 del CEDH y del art. 1 del Protocolo 1; y que corresponde al CM supervisar que las autoridades de Ucrania cumplan la obligación de hacer efectivas las sentencias que dicten sus tribunales internos contra el propio Estado o contra empresas estatales. Tanto respecto de los demandantes como con relación a otros miles de demandas - 12146 [sic] — que todavía no han recibido respuesta por parte del TEDH. En su opinión disidente, los siete jueces critican duramente que el TEDH haya optado por no dictar sentencia en miles de demandas individuales, remitiendo la respuesta a cada una de esas demandas a la labor de supervisión que corresponde a un órgano político como es el CM. Para este grupo de jueces este fallo supone negar a cada uno de esos miles de demandantes el derecho que les confiere el CEDH de presentar una demanda ante el TEDH y que este se pronuncie, abandonándolos en un limbo legal (párr. 41). La documentación relativa a la ejecución de esta sentencia se puede consultar en la base de datos sobre la 
los efectos de que el Estado cumpla la sentencia y también garantice el cumplimiento del CEDH para evitar así la repetición en el futuro de vulneraciones de este convenio. Por esta vía, el Tribunal «dispone de un cierto control en cuanto a la forma en que se ejecutan sus sentencias» (Morte Gómez, 2011: 235). Tanto en un supuesto como en el otro, tales indicaciones deben ser tenidas en cuenta por el CM en su labor de supervisión, a la hora de valorar si el Estado ha ejecutado la sentencia dictada en su contra ${ }^{16}$.

Lo que no obsta para que, al mismo tiempo, en su jurisprudencia el TEDH por regla general procure mostrarse muy respetuoso con los poderes de supervisión de la ejecución de sus propias sentencias que se atribuyen al $\mathrm{CM}$ de conformidad con el art. 46 del CEDH. Por ello, se declara incompetente para conocer de las demandas que se presenten contra un Estado miembro alegando exclusivamente que ha vulnerado el art. 46.1 al no ejecutar una sentencia del TEDH. No hace mucho, en Moreira Ferreira v. Portugal (no. 2) el TEDH «reiterates that the question of compliance by the High Contracting Parties with its judgments falls outside its jurisdiction if it is not raised in the context of the "infringement procedure" provide for in Article 46.4 and 5 of the Convention ${ }^{17}$. Aunque esta toma de posición no resuelve ni mucho menos todos los problemas de interpretación que se pueden plantear en concreto en aquellos supuestos en los que los Estados no han ejecutado la sentencia del TEDH y se han producido hechos o informaciones nuevas que afectan al caso pendiente de ejecución (por ejemplo, una nueva sentencia de los tribunales internos de ese Estado que afecte a ese mismo caso), que pueden justificar que se admita una nueva demanda relativa al mismo caso ${ }^{18}$.

ejecución de las sentencias, HUDOC (http://hudoc.exec.coe.int/eng); en concreto, por lo que se refiere a este caso, en https://bit.ly/2NrBjsZ.

16 Comité de Ministros (2016: 290-291); Comité de Ministros (2017: 254-255); Fortas (2015: 54-57, 79-84 y 185 y ss.), y Sudre (2017: 917 y ss.).

17 Sentencia de la Gran Sala de 11 de julio de 2017 (ECLI:CE:ECHR:2017:0711JUD001986712), párr. 102 y párrs. 47 y ss., y las interesantes opiniones disidentes que acompañan relativas al alcance de los poderes del TEDH a la hora de establecer en sus sentencias las medidas generales y particulares que deben cumplir los Estados partes para cesar y reparar la vulneración del CEDH, y la relación de las mismas con la competencia de supervisión de la ejecución de las sentencias que corresponde al CM.

18 En esta dirección, en la Sentencia de 11 de octubre de 2011, Emre v. Switzerland (N. ${ }^{o}$ 2) (ECLI:CE:ECHR:2011:1011JUD000505610), la Sala decidió que Suiza había vulnerado el art. 8 conjuntamente con el art. 46 del CEDH, en un caso cuyo origen se sitúa en la expulsión del demandante de Suiza por una serie de hechos delictivos de poca envergadura. Ante estos hechos, mediante Sentencia de 22 de mayo de 2008, 
Conviene señalar que mientras el $\mathrm{CM}$ no considere que el Estado ha ejecutado la sentencia del TEDH, el caso continuará incluido en la agenda de este órgano como pendiente de llevar a cabo la ejecución (norma 7). Lo que a su vez podría valorarse como una suerte de «sanción" política o moral contra el Estado recalcitrante a la ejecución de la sentencia. Como se comprobará (III y IV), la presión inter pares que puede derivarse a lo largo del procedimiento de supervisión y el reconocimiento público por parte del CM de que un caso sigue pendiente de ejecución año tras año constituye la principal «sanción» que hasta ahora se ha aplicado en los supuestos de la Federación de Rusia y de Turquía, a pesar del incumplimiento crónico de un buen número de sentencias por estos dos Estados.

A este respecto, se debe insistir en la publicidad que caracteriza a todo el procedimiento, a salvo la naturaleza confidencial de las deliberaciones del CM en virtud del art. 21 del Estatuto de Londres y de que el propio CM decida otra cosa «en orden a proteger intereses legítimos públicos o privados» (norma 8). De este modo, la publicidad de todo el procedimiento se convierte en la práctica en el principal instrumento de presión que recae sobre el Estado responsable de la ejecución de la sentencia. Si bien el enfoque que preside todo el procedimiento se basa en la colaboración que se reciba de las autoridades estatales, la conducta de estas últimas se ve sometida al escrutinio del que podrán ser objeto por parte de las instituciones públicas internacionales e internas y

Emre v. Switzerland (ECLI:CE:ECHR:2008:0522JUD004203404), el TEDH había decidido que se había vulnerado el art. 8, teniendo en cuenta los vínculos familiares y sociales que el demandante mantenía en Suiza. Tras esta última sentencia, los tribunales suizos volvieron a conocer del caso y decretaron que el demandante no podía volver a residir en Suiza durante un periodo de diez años. El demandante presentó una nueva demanda en Estrasburgo en la que alegaba la vulneración de los arts. 8 y 46.1 de la CEDH, al incumplir las autoridades suizas la primera sentencia dictada por el TEDH. En su respuesta, la Sala entra a valorar si Suiza ha cumplido o no la primera sentencia y llega a la siguiente conclusión: «The Court finds that most natural execution of its judgment, and that which would best corresponde to the principle of restitutio in integrum, would have been to annul purely and simply, with immediate effect, the exclusion measure ordered against the applicant. Even assuming that another result would have been acceptable, the Court is of the view that the binding force of its judgments under Article 46.1 and the importance of their effective execution, in good faith and in a manner compatible with the 'conclusions and spirit' of the judgment, necessarily required, in the circumstances of the case, a more indepth examination of the considerations set out in the Court's first judgment» (párr. 75). Por lo que la decisión de expulsarlo durante diez años vulnera el art. 8 valorado conjuntamente con el art. 46 del CEDH. 
de los actores no gubernamentales dedicados a la promoción y protección de los derechos humanos, quienes podrán consultar toda la información relativa al procedimiento de supervisión de la sentencia en la web del Consejo de Europa, con bastante facilidad de acceso y rapidez por lo que se refiere a la actualización de contenidos ${ }^{19}$.

En este orden de cosas, a la hora de examinar la información que le proporciona el Estado declarado infractor por el TEDH, el CM puede tener en cuenta la información proveniente de: a) la parte que soporta la vulneración del CEDH; b) cualquier ONG o institución nacional (defensor del pueblo...); c) cualquier organización internacional o cualquiera de los órganos o agencias de esta, y d) cualquier institución u órgano que haya intervenido

19 Por ejemplo, de los 31 casos pendientes de ejecutar por parte de España a 31 de diciembre de 2017, en el informe del CM de 2017 (pp. 102 y 170) se califica como único main case pendiente, al que se está aplicando el subprocedimiento reforzado, la Sentencia de 22 de abril de 2014, A. C. and Others v. Spain (ECLI:CE:ECHR:2014:0422JUD000652811), en la que se declara que España ha vulnerado el art. 13 en relación con los arts. 2 y 3 del $\mathrm{CEDH}$, respecto de un grupo de demandantes de protección internacional de origen saharaui que iban a ser expulsados a Marruecos a pesar de que alegaban que su vida y/o su integridad física estaban en peligro si se les expulsaba al Estado magrebí. El TEDH, de conformidad con el art. 46 del CEDH, mantiene lo siguiente: «Habida cuenta de las circunstancias particulares del asunto y teniendo en cuenta el hecho de que la violación del artículo 13 del Convenio resulta de la falta del carácter suspensivo de los procedimientos judiciales relativos a las solicitudes de protección internacional presentadas por los demandantes, y del hecho de que están aún pendientes a día de hoy, habiendo llegado los primeros demandantes solicitantes de asilo a España en enero de 2011, el TEDH estima que el Estado demandado deberá garantizar, jurídica y materialmente, mantener a los demandantes en territorio español durante el examen de sus causas y hasta tanto la decisión interna definitiva en cuanto a sus solicitudes de protección internacional sea pronunciada» (párr. 112). En este sentido, en los dos planes de acción que fueron enviados por España al CM, el 21 de noviembre de 2015 y el 15 de marzo de 2018, se da cuenta en particular de la situación en la que se encuentra cada uno de los demandantes y con carácter general de la jurisprudencia del TS relativa a la aplicación de la normativa sobre asilo y protección subsidiaria, en concreto por lo que se refiere a la garantía de la existencia del derecho a un recurso efectivo. Los dos planes de acción, así como todo la documentación sobre la supervisión de la ejecución de esta sentencia, pueden ser consultados en: http://hudoc.exec.coe.int/ENG\#\{“EXECAppno”:[“6528/11”]\}. Para los datos globales sobre la aplicación a España del procedimiento de supervisión, se puede consultar el Country Factsheet elaborado por el Servicio de Ejecución, en el que se contabilizan veinticinco casos pendientes de ejecutar por parte de España a 30 de junio de 2018. Disponible en: https://rm.coe.int/1680709746. 
durante el procedimiento ante el TEDH, ya sea porque tienen derecho a intervenir (en particular el Comisario de Derechos Humanos), ya sea por invitación del propio TEDH. Toda la información que se reciba desde estas fuentes deberá ser transmitida al Estado y hecha pública en la página web (norma 9).

El CM se ve obligado así, en buena medida, a aplicar el principio contradictorio en el desarrollo de este procedimiento de supervisión. A la vista de la información proporcionada por el Estado infractor y por la parte que soporta la vulneración del CEDH, y también por las diversas fuentes que se acaban de mencionar, el CM puede adoptar resoluciones provisionales con el objetivo de "provide information on the state of progress of the execution or, where appropriate, to express concern and/or to make suggestions with respect to the execution» (norma 16).

En definitiva, y como se comprobará en los siguientes epígrafes dedicados a la Federación de Rusia y Turquía, la efectividad del procedimiento de supervisión esencialmente descansa en la colaboración que se obtenga de las autoridades estatales, a las que les corresponde poner en práctica las medidas propuestas por el CM en sus resoluciones provisionales. En la práctica, como principal «sanción» las autoridades estatales se podrán ver sometidas a la presión política que se derive del desarrollo del procedimiento de supervisión en el seno del CM y de la publicidad de toda la información referida al mismo.

Si bien, en las Normas de Ejecución se incluye la posibilidad de que el $\mathrm{CM}$ interponga ante el TEDH los recursos de interpretación (norma 10) y de incumplimiento (norma 11), de conformidad con lo dispuesto en el citado art. 46.3 y 4 del $\mathrm{CEDH}$, en ambos casos si se alcanza una mayoría de dos tercios de los votos de los representantes que tengan derecho a formar parte del CM. El recurso de interpretación puede ser interpuesto por el CM durante cualquier fase del procedimiento de supervisión, mediante una resolución provisional, que deberá ser motivada y deberá reflejar los diferentes puntos de vista que se hayan manifestado en el seno del CM y en particular el del Estado infractor del CEDH según el TEDH ${ }^{20}$. Hasta la fecha nunca se ha interpuesto este recurso ${ }^{21}$.

20 Tanto en este recurso, como en el supuesto de que se interponga un recurso por incumplimiento, «el Comité de Ministros estará representado ante el TEDH por su Presidente», salvo que se decida otra cosa por mayoría de dos tercios de los miembros que hayan ejercido su derecho a voto y mayoría de los representantes que tengan derecho a formar parte del CM.

21 En los arts. 91 a 93 del Reglamento del TEDH — la última versión de 16 de abril de 2018 - se regula el procedimiento aplicable al recurso de interpretación previsto en el art. 46.3 del CEDH. Véase: https://www.echr.coe.int/Documents/Rules_Court_ ENG.pdf. 
Por lo que se refiere al recurso por incumplimiento, solo se puede interponer «en circunstancias excepcionales» (norma 11), pero no se ofrece ninguna explicación sobre qué tipo de circunstancias pueden considerarse como de «excepcionales» a los efectos de que sea interpuesto este recurso; por lo que la existencia o no de tales circunstancias deberá ser decidida por un órgano de naturaleza política como es el CM. Asimismo, se condiciona la interposición de este recurso a que, mediante una resolución provisional, se le notifique previa y formalmente al Estado declarado infractor por la sentencia que no ha ejecutado, con una antelación de seis meses, salvo que el CM decida otra cosa. Con posterioridad, la interposición del recurso se llevará a cabo mediante una resolución provisional, que deberá ser motivada y en la que se deberá incluir, de forma concisa, la postura jurídica que mantenga el Estado concernido ${ }^{22}$.

Hasta la fecha el recurso por incumplimiento solo se ha interpuesto en una ocasión, a causa de la no ejecución de la sentencia de 22 de mayo de 2014, Ilgar Mammadov v. Azerbaijan ${ }^{23}$, pendiente de respuesta por el TEDH en el momento de ser redactadas estas líneas. Por tanto, en los últimos ocho años el $\mathrm{CM}$ solo ha considerado que se daban tales circunstancias excepcionales en un único caso, en el que motivos para interponerlo desde luego no faltan ${ }^{24}$. Pero

22 En los arts. 94 a 99 del citado reglamento del TEDH se regula el procedimiento aplicable al recurso por incumplimiento previsto en el art. 46.4 y 5 del CEDH.

23 ECLI:CE:ECHR:2014:0522JUD001517213.

24 Con la citada sentencia se condena a Azerbaiyán por vulnerar los arts. 5.1, 5.4, 6.2 y 18 en relación con el art. 5, al detener preventivamente al demandante desde el 4 de febrero de 2013, sin respetar las garantías que preceptúan los citados preceptos por lo que se refiere a la privación de libertad. Han transcurrido más de tres años desde que el TEDH dictó sentencia y el demandante ha continuado en prisión durante todo este tiempo. Además, ha sido juzgado por los tribunales de este Estado y condenado a siete años de prisión, a través de un procedimiento judicial que no respeta el art. 6.2 del $\mathrm{CEDH}$, como se certifica con la Sentencia de 16 de noviembre de 2017, Ilgar Mammadov v. Azerbaijan (N. ${ }^{\circ}$ 2) (ECLI:CE:ECHR:2017:1116JUD000091915), con la que se condena a este Estado a pagar al demandante un total de 10000 euros en concepto de satisfacción equitativa por el daño no pecuniario. Por tanto, no hay ninguna duda de que Azerbaiyán ha hecho caso omiso a lo dispuesto por el TEDH en su citada sentencia de 2014 (excepto por lo que se refiere al pago de 20000 euros como satisfacción equitativa y 2000 euros en concepto de costas); y también a los requerimientos del CM para que ponga inmediatamente en libertad al demandante, a través de las resoluciones provisionales CM/ResDH(2015)43, CM/ResDH(2015)156 y $\mathrm{CM} / \operatorname{ResDH}(2016) 144$. En esta última se afirma que «it is intolerable that, in a State subject to the rule of law, a person should continue to be deprived of his liberty on the basis of proceedings engaged, in breach of the Convention, with a view to punishing 
como se comprobará en los epígrafes III y IV, el CM también podría haber apreciado la existencia de circunstancias excepcionales en un buen número de casos referidos a la Federación de Rusia y a Turquía. Sin embargo, hasta hoy no ha decidido hacer uso del art. 46.4 con relación a estos dos Estados.

Por último, si el CM considera que el Estado ha aplicado todas las medidas necesarias para dar cumplimiento a la sentencia, adoptará una resolución final, con la que dará por finalizado el procedimiento de supervisión que le encomiendan los arts. 46.2 y 39.4 del CEDH. En el epígrafe $V$ se ofrecerá una valoración general de la labor de supervisión que corresponde al CM, siempre a la luz de la práctica relativa a la Federación de Rusia y a Turquía. Ahora se puede apuntar que en alguna medida la resolución final que debe adoptar el CM se constituye como el resultado de una especie de "Quinta Instancia». A cargo, eso sí, de un órgano político, ya que al CM le corresponde decidir si el Estado declarado infractor cumple o no con lo establecido en la sentencia dictada por el TEDH. Esta función del CM se puede calificar de cuasi jurisdiccional (Fortas, 2015: 61 y 185 y ss., y 451 y ss.).

him for having criticised the government». El CM, mediante la Resolución Provisional CM/ResDH (2017)379, comunica a Azerbaiyán que va a interponer el recurso por incumplimiento y le da de plazo hasta el 29 de noviembre para que de forma concisa le manifieste su punto de vista sobre este tema; y el 5 de diciembre de 2017, una vez recibida la contestación de Azerbaiyán, adopta la Resolución Provisional CM/ ResDH (2017)429, con la que presenta el recurso por incumplimiento (véase: https:// bit.ly/2OGhD9p). Cabe añadir que la más que deficiente situación en materia de derechos humanos por la que atraviesa esta antigua República Soviética ha servido de justificación para que el secretario general del Consejo de Europa aplique el art. 52 del CEDH respecto de este Estado, precepto en el que se prevén las «indagaciones del Secretario General», con el siguiente tenor literal: «A requerimiento del Secretario General del CoE, toda Alta Parte Contratante suministrará las explicaciones pertinentes sobre la manera en que su derecho interno asegura la aplicación efectiva de las disposiciones de este Convenio» (véase https://bit.ly/1NpPP09). Más en particular, recientemente se han hecho públicas las denuncias de corrupción contra el que fuera presidente de la Asamblea Parlamentaria del Consejo de Europa, el senador español Pedro Agramunt, quien según tales denuncias recibió dinero y diversos regalos por parte de las autoridades de este Estado a cambio de que consiguiera «suavizar» los informes y en general todas las actividades que sobre la situación de los derechos humanos en Azerbaiyán se llevarán a cabo en el seno de esta OI. La Asamblea Parlamentaria ha decidido inhabilitarle por un periodo de diez años para ser observador electoral o para ser presidente o vicepresidente de las comisiones o subcomisiones que actúan en su seno (véase: https://bit.ly/2Ry5e5W). 
Porque se trata, en definitiva, de volver a valorar jurídicamente si finalmente el Estado cumple o no el $\mathrm{CEDH}$, tras la sentencia dictada por el TEDH en su contra. A través de un nuevo procedimiento, de naturaleza en alguna medida mixta, en parte técnica - Servicio de Ejecución-y en parte política - $\mathrm{CM}$ - Pero se trata de un procedimiento cuyo órgano decisorio principal, el CM, es de carácter claramente intergubernamental, al que corresponde determinar jurídicamente si el Estado ha ejecutado o no la sentencia. Labor que se concreta a través de las resoluciones provisionales y las resoluciones finales. En la práctica se puede apreciar una tendencia en el sentido de que los Estados partes en el CEDH y el propio TEDH consideran que las resoluciones provisionales y las resoluciones finales que adopta el CM son jurídicamente vinculantes. $\mathrm{E}$ incluso se puede sostener que tales resoluciones crean doctrina de cosa ejecutada, en el sentido de que sientan doctrina sobre cómo se debe llevar a cabo el cumplimiento de la sentencia del TEDH y por ende de las disposiciones del CEDH declaradas infringidas por el Tribunal de Estrasburgo en casos más o menos concretos (Fortas, 2015: 61 y 185 y ss.). Pero como se comprobará a continuación, no siempre el procedimiento de supervisión que protagoniza el $\mathrm{CM}$ ofrece buenos resultados. $\mathrm{Al}$ menos con relación a una considerable parte de las sentencias dictadas contra la Federación de Rusia y Turquía, el procedimiento puede durar un buen número de años e incluso en algunos casos puede prolongarse su aplicación sine die.

\section{LA PRÁCTICA QUE CONCIERNE A LA FEDERACIÓN DE RUSIA}

Desde un punto de vista meramente cuantitativo, los datos correspondientes a los dos últimos años son por sí solos bastante elocuentes. A 31 de diciembre de 2016, se contabilizan un total de 1573 casos pendientes de ejecución en los que se había concluido la vulneración del CEDH por parte de la Federación de Rusia (Comité de Ministros, 2016: 59). A 31 de diciembre de 2017, los casos pendientes alcanzan la cifra de 1689: 216 leading cases $^{25}$ y 1473 repetitive cases $^{26}$ (Comité de Ministros, 2017: 66).

Siempre por lo que se refiere a la Federación de Rusia, en 2016 se cerraron un total de 261 casos: 4 leading cases y 257 repetitive cases (Comité de Ministros, 2016: 61). En 2017 se cerraron 254 casos; 14 leading cases y 240

2559 dentro del subprocedimiento reforzado, 151 dentro del estándar y 6 pendientes de clasificar.

26977 dentro del reforzado, 386 dentro del estándar y 110 estaban pendientes de clasificar. 
repetitive cases (Comité de Ministros, 2017: 71). A ese ritmo de resolución, si no se presentaran nuevos casos para supervisar su ejecución, el CM necesitaría más de media década para cerrar el total de casos pendientes. Ahora bien, a la vista del balance anual de leading cases cerrados — 4 en 2016 y 14 en 2017-, la previsión de tiempo necesario para cerrar todos los leading cases pendientes puede superar una década.

Pero además, se debe tener en cuenta que en 2016 se transmitieron 283 nuevos casos en los que el TEDH concluye que la Federación de Rusia ha vulnerado el CEDH: 8 leading cases y 275 repetitive cases (Comité de Ministros, 2016: 56). Y en 2017 se transmitieron 370 nuevos casos: 19 leading cases y 351 repetitive cases (Comité de Ministros, 2017: 61). En total, desde que la Federación de Rusia es parte en el CEDH (desde el 5 de mayo de 1998) hasta abril de 2018, se han transmitido al CM 2380 casos relativos a este Estado, de los cuales han sido cerrados mediante resolución final un total de $608^{27}$. Con estos datos, todo apunta a que el número de casos pendientes de ejecución que conciernen a la Federación de Rusia puede mantenerse por encima del millar durante al menos la próxima década.

Cabe añadir a este respecto que según las estadísticas que se ofrecen en el citado informe de 2016, por lo que se refiere a los casos cerrados en ese mismo año, la Federación de Rusia tardó una media de 10,2 años [sic] en ejecutar las sentencias de casos incluidos dentro del subprocedimiento reforzado, y 1,2 años en ejecutar las sentencias de casos incluidos dentro del estándar (Comité de Ministros, 2016: 71) ${ }^{28}$. Por otra parte, en 2016 la Federación de Rusia pagó un total de 7380062 euros para hacer efectivas las cantidades previstas como satisfacción equitativa en las sentencias dictadas en su contra (ibid.: 76). En 2017 la cifra pagada por este concepto alcanzó los 14552886 euros (Comité de Ministros, 2017: 81)

Desde una óptica cualitativa, que atiende a la naturaleza inderogable de los derechos humanos que han sido vulnerados, dentro de la lista de los principales casos pendientes de ejecución se pueden destacar, en primer lugar, los 252 casos agrupados en torno a Khashiyev et Akayeva v. Russia ${ }^{29}$. Se trata de un grupo de casos referidos a violaciones, entre otras, de los arts. 2, 3 y 13 del

27 Country Factsheet sobre la Federación de Rusia, disponible en: https://rm.coe.int/russian-factsheet/1680764748.

28 Esta estadística ya no se incluye en el informe de 2017, en el que se limita a contabilizar los leading cases pendientes de ejecución con un plazo de tiempo superior a los cinco años desde que la sentencia es definitiva; un total de 43 a los que se aplica el subprocedimiento reforzado, y un total de 107 a los que se aplica el estándar (Comité de Ministros, 2017: 77).

29 Sentencia de 24 de febrero de 2005 (ECLI:CE:ECHR:2005:0224JUD005794200). 
$\mathrm{CEDH}$, cometidas por el ejército y las fuerzas de seguridad rusas en el contexto de operaciones antiterroristas en el Cáucaso, principalmente en Chechenia. En particular, tales vulneraciones son consecuencia del uso desproporcionado de la fuerza, desapariciones, detenciones arbitrarias, tortura y tratos inhumanos, investigaciones ilegales y destrucción de la propiedad. Respecto de este grupo de casos, durante los más de doce años que han transcurrido desde que se dictó la citada sentencia, las investigaciones realizadas por las autoridades rusas no han dado ningún resultado y no ha habido recursos internos efectivos a disposición de las víctimas, como ha reconocido el CM $(2017: 137-138)^{30}$.

Este clima de impunidad se ha vuelto a poner de manifiesto respecto de casos planteados más recientemente ante el TEDH. En este sentido, en la selección de las sentencias dictadas en los dos últimos años que contienen indicaciones relevantes sobre cómo el Estado infractor debe llevar a cabo su ejecución, el CM ha seleccionado Abakarova v. Russia ${ }^{31}$, relativa a hechos del mismo tipo de los que han dado lugar a los mencionados 252 casos agrupados en torno a Khashiyev et Akayeva. En Abakarova el TEDH llega a la conclusión de que las autoridades rusas no han investigado efectivamente las denuncias de uso desproporcionado de la fuerza en el contexto de las operaciones terroristas en Chechenia: los procedimientos penales no han permitido ni siquiera establecer los hechos, ni se han establecido las responsabilidades administrativas o penales de los responsables, ni se les ha sancionado (párrs. 111-114). Por su parte, el CM confirma estas conclusiones (Comité de Ministros, 2016: 130-131).

En esta misma dirección y en segundo lugar, en Finogenov and Others $v$. Russia $^{32}$ se declara que la Federación de Rusia vulnera el art. 2, como consecuencia de la actuación de sus fuerzas de seguridad durante la operación de rescate que tuvo lugar en un teatro de Moscú en octubre de 2002. Aunque las autoridades rusas han hecho efectiva la satisfacción equitativa de 1254000 euros a repartir entre los 63 demandantes, hasta la fecha no ha habido investigaciones efectivas para establecer las responsabilidades penales y/o administrativas por los hechos ocurridos ${ }^{33}$. Más recientemente, en Tagayeva and Others $v$. Russia $^{34}$ se condena a la Federación de Rusia por vulnerar el art. 2 en el contex-

30 Toda la documentación relativa al procedimiento de supervisión aplicado a estos 252 casos - Plan de Acción presentado por el Gobierno ruso, decisiones del Comité de Ministros, comunicaciones de ONG...- puede ser consultada en: https://bit.ly/2E4Dp2G.

31 Sentencia de 15 de octubre de 2015 (ECLI:CE:ECHR:2015:1015JUD001666407).

32 Sentencia de 20 de diciembre de 2011 (ECLI:CE:ECHR:2011:1220JUD001829903).

33 https://bit.ly/2OF9xy2.

34 Sentencia de 13 de abril de 2017 (ECLI:CE:ECHR:2017:0413JUD002656207). 
to de la operación de rescate de rehenes durante el ataque terrorista que tuvo lugar en un colegio en Beslan, en Osetia del Norte en septiembre de 2004, en la que fallecieron 334 personas, incluidos 186 niños. En su fallo en esta última sentencia el TEDH establece la suma de dinero que debe pagarse a cada uno de los demandantes en concepto de satisfacción equitativa y de costas y gastos, y además indica toda una batería de medidas, por una parte dirigidas a investigar y sancionar las violaciones del art. 2 con relación a los demandantes y, por otra, destinadas a prevenir nuevas violaciones en el futuro. Medidas cuya efectiva aplicación corresponde supervisar al CM de conformidad con el art. 46 del CEDH, como insiste el propio TEDH (párrs. 635-641). El CM ha agrupado los dos mencionados casos a los efectos de aplicar el procedimiento de supervisión ${ }^{35}$.

También merecen ser destacados, en tercer lugar, los 116 casos agrupados en torno a Mikheyev v. Russia ${ }^{36}$, pendientes de ejecutar durante los últimos 12 años. En este grupo de casos se condena a la Federación de Rusia por torturas y/o tratos crueles, inhumanos o degradantes de personas que estaban bajo la custodia de la policía, y la falta de investigaciones efectivas sobre estos hechos (arts. 3 y 13, este último en relación con el primero) ${ }^{37}$. Por último y sin intención de exhaustividad, se puede traer a colación el caso Dobriyeva and Others v. Russia ${ }^{38}$, en el que se declara que la Federación de Rusia ha vulnerado el art. 2 del CEDH, por la falta de investigación efectiva de las desapariciones en San Petersburgo de 4 personas que provienen de la República de Ingushetia, sin que durante los cuatro años que han transcurrido desde que se dictó esta sentencia las autoridades rusas hayan cesado y reparado el hecho ilícito internacional cometido ${ }^{39}$.

En definitiva y como se insistirá en el epígrafe V, la práctica brevemente estudiada por lo que se refiere a la Federación de Rusia pone de manifiesto

35 Véase: https://bit.ly/2Pk0teT. Según se pronuncia el CM en su 1265 reunión en referencia a la ejecución de la sentencia dictada en Finogenov, aunque valora positivamente el pago de la satisfacción equitativa, la publicidad y difusión de la sentencia y la adopción de medidas generales dirigidas a evitar que se vuelvan a repetir los mismos hechos; «It is noted with regret that subsequent to the European Court's judgment, which criticised an earlier decision not to open a criminal investigation, the investigating authorities decided to maintain the decision not to investigate. The decision not to investigate did not, therefore, give effect to the Court's judgment» (véase: https://bit.ly/2QwsHmT).

36 Sentencia de 26 de enero de 2006 (ECLI:CE:ECHR:2006:0126JUD007761701).

37 Véase: https://bit.ly/2zWO0IN.

38 Sentencia de 19 de diciembre de 2013 (ECLI:CE:ECHR:2013:1219JUD001840710).

39 Véase: https://bit.ly/2zWvjVB. 
las evidentes limitaciones que presenta el sistema de protección internacional establecido por el CEDH en supuestos en los que se producen vulneraciones graves y masivas de los derechos humanos decididas o al menos toleradas por las propias autoridades civiles o militares del Estado. Por lo general, hasta la fecha las autoridades estatales no han colaborado en la ejecución de las sentencias del TEDH en las que se solicita la investigación de los hechos y la sanción administrativa y/o penal de los principales responsables de tales vulneraciones. Sin perjuicio de que en algunos casos abonen las cantidades de dinero que corresponden en concepto de satisfacción equitativa.

Lo que no obsta para que, en otros supuestos en los que no está en juego la vulneración de los derechos considerados como de inderogables por el art. 15 del $\mathrm{CEDH}$, las autoridades rusas demuestren una mayor colaboración con el CM a la hora de ejecutar las sentencias dictadas en su contra por el TEDH. Por ejemplo y entre otros, en 2017 el CM cerró, trece años después de dictarse la sentencia, los 105 casos agrupados en torno a Kormacheva v. Russia ${ }^{40}$, relativos a la vulneración de los arts. 6 y 13 del CEDH, dada la excesiva lentitud de los procedimientos judiciales penales y civiles y la falta de un recurso efectivo (Comité de Ministros, 2017: 116 y 190-191) ${ }^{41}$.

\section{LA PRÁCTICA REFERIDA A TURQUÍA}

Las cuentas que corresponden a Turquía también evidencian el deficiente balance que ofrecen las autoridades de este Estado en este ámbito. A 31 de diciembre de 2016, se contabilizan un total de 1430 casos pendientes de ejecución en los que se ha concluido la vulneración del CEDH por parte de Turquía (Comité de Ministros, 2016: 59). Un año después la cifra de casos

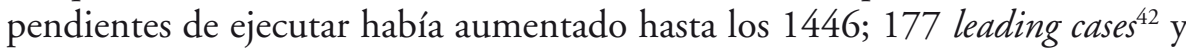
1269 repetitive cases $^{43}$ (Comité de Ministros, 2017: 66).

Siempre por lo que se respecta a Turquía, en 2016 se cerraron 274 casos: 11 leading cases, y 263 repetitive cases (Comité de Ministros, 2016: 61). Y en 2017 se cerraron 123 casos: 23 leading cases y 100 repetitive cases (Comité de Ministros, 2017: 71) A este ritmo de resolución, si no se presentaran nuevos casos para supervisar su ejecución, el CM necesitaría alrededor de siete u ocho años para cerrar todos los casos pendientes. Ahora bien, si solo se tiene

\footnotetext{
40 Sentencia de 29 de enero de 2004 (ECLI:CE:ECHR:2004:0129JUD005308499).

41 Véase: https://bit.ly/2zWqjAz.

4236 dentro del reforzado, 136 dentro del estándar y 5 pendientes de clasificación.

43442 dentro del reforzado, 774 dentro del estándar y 53 pendientes de clasificar.
} 
en cuenta el balance anual de leading cases cerrados - 11 en 2016 y 23 en 2017_, la previsión de tiempo necesario para cerrar todos los leading cases puede alcanzar más de una década.

Pero además en 2016 se transmitieron 114 nuevos casos relativos a Turquía: 15 leading cases y 99 repetitive cases (Comité de Ministros, 2016: 56). Y en 2017 otros 138 nuevos casos: 14 leading cases y 124 repetitive cases (Comité de Ministros, 2017: 61). Por lo que a los datos globales se refiere, desde que Turquía aceptó la competencia de la entonces Comisión para presentar demandas individuales el 28 de enero de 1987, hasta abril de 2018, se han transmitido un total de 3735 casos al CM, de los cuales 2304 se han cerrado mediante resolución final ${ }^{44}$. Con estos datos, todo apunta a que el número de casos pendientes de ejecución que conciernen a Turquía puede mantenerse por encima del millar durante la próxima década.

Cabe añadir que por lo que se refiere a los casos cerrados en 2016, Turquía tardó una media de 13,5 años [sic] en ejecutar las sentencias de casos incluidos dentro del subprocedimiento reforzado, y de 4,8 años en ejecutar las sentencias de casos incluidos dentro del estándar (Comité de Ministros, 2016: $71)^{45}$. Por otra parte, en 2016 Turquía pagó un total de 20743112 euros para hacer frente a la satisfacción equitativa prevista en las sentencias dictadas en su contra por el TEDH, siendo el Estado que más dinero abonó por ese concepto, seguido de Italia ${ }^{46}$ y de la Federación de Rusia (ibid:: 2016: 76). En 2017 la suma pagada por Turquía en concepto de satisfacción equitativa alcanzó los

44 Country Factsheet de Turquía, disponible en: https://rm.coe.int/1680709767.

45 Como ya se ha señalado, esta estadística desaparece en el informe de 2017, en el que si bien sí se ofrecen los datos referidos a los leading cases pendientes de ejecución con un plazo de tiempo superior a los cinco años; un total de 24 a los que se aplica el subprocedimiento reforzado y un total de 92 a los que se aplica el estándar (Comité de Ministros, 2017: 77).

46 Con un total de 15127536 euros (Comité de Ministros, 2016: 75). En los últimos años Italia es uno de los Estados que se sitúa en los primeros puestos del orden de prelación por lo que al número sentencias condenatorias se refiere. La gran mayoría de ellas certifican jurídicamente los graves problemas que afectan a la administración de justicia en el país transalpino, con muy prolongados retrasos en la resolución de los casos que se plantean ante sus tribunales. Se pueden consultar a este respecto los principales casos seleccionados pendientes por país en el citado informe de 2016 (ibid.: 2016: 86-87), entre los que destacan, entre otros, un total de 1725 casos [sic] agrupados en torno a Ceteroni v. Italy, Sentencia de 15 de noviembre de 1996 (ECLI:CE:ECHR:1996:1115JUD002246193), en los que se condena a Italia por la excesiva lentitud de los procedimientos civiles. 
11580458 euros, pasando a ser el tercer Estado en la lista, por detrás de la Federación de Rusia y de Italia (Comité de Ministros, 2017: 81).

Desde una óptica cualitativa, que atiende a la naturaleza inderogable de los derechos humanos vulnerados, de la lista de los principales casos pendientes de ejecución durante los últimos diez o doce años, se pueden destacar, en primer lugar, los 130 casos agrupados en torno a Bati and Others v. Turkey ${ }^{47}$ y Okkali v. Turkey ${ }^{48}$. En este grupo de casos se concluye la vulneración de los arts. 2 - derecho a la vida- 3 - prohibición de la tortura—y 13 -derecho a un recurso efectivo- del CEDH, por actuaciones de las fuerzas de seguridad turcas y la ausencia de investigaciones efectivas por parte de las autoridades de este país ante tales vulneraciones (Comité de Ministros, 2017: 103 y 139). Sobre Bati el CM, entre otras cuestiones, advierte lo siguiente: «[...] the $\mathrm{CM}$ recalled its consistent position that respondent States have a continuing obligation to conduct effective investigations into alleged abuses by members of security forces and encouraged the authorities to give full effect to Article 90 of the Turkish Constitution by conducting ex officio evaluations as to the reopening of investigations in this group» (Comité de Ministros, 2016: $131)^{49}$.

En segundo lugar, merece ser mencionado el caso interestatal Cyprus v. Turkey, resuelto mediante las sentencias de la Gran Sala de 10 de mayo de 2001 (fondo) $^{50}$ y de 12 de mayo de 2014 (satisfacción equitativa) ${ }^{51}$. En este caso se condena a Turquía por vulnerar, entre otras disposiciones, los arts. 2, 3 y 5 del CEDH en relación a las 1485 personas desaparecidas a raíz de la invasión del norte de Chipre por las tropas turcas en 1974. Muy vinculado con Varnava v. Turkey ${ }^{52}$, en el que se declara que Turquía de nuevo ha vulnerado los arts. 2, 3 y 5 del CEDH al no investigar efectivamente la desaparición de nueve chipriotas también durante la ocupación armada del norte de Chipre. Se trata de grupo de sentencias cuya ejecución sigue pendiente a fecha de hoy, hasta el punto de que Turquía ni siquiera ha hecho efectiva la satisfacción equitativa decidida por el TEDH (Comité de Ministros, 2016: 265-267 y Comité de Ministros, 2017: 244-246) ${ }^{53}$.

47 Sentencia de 3 de junio de 2004 (ECLI:CE:ECHR:2004:0603JUD003309796).

48 Sentencia de 17 de octubre de 2006 (ECLI:CE:ECHR:2006:1017JUD005206799).

49 Véase: https://bit.ly/2zW02lB.

50 ECLI:CE:ECHR:2001:0510JUD002578194.

51 ECLI:CE:ECHR:2014:0512JUD002578194.

52 Sentencia de la Gran Sala de 18 de septiembre de 2009 (ECLI:CE:ECHR:2009:0918JUD001606490).

53 Véase: https://bit.ly/2C4dshc y https://bit.ly/2C0VTyk, respectivamente. 
En tercer lugar, los 37 casos agrupados en torno a Erdogan and Others $v$. Turkey $^{54}$, y Kasa v. Turkey ${ }^{55}$, en los que se condena a Turquía por las vulneraciones de los arts. 2 y 13, cometidas por sus tropas durante operaciones contra grupos terroristas, sobre todo en la región del Kurdistán, y la falta de investigación efectiva de las mismas por parte de las autoridades turcas (Comité de Ministros, 2016: 93-94 y Comité de Ministros, 2017: 103 y 140). Sobre los citados casos agrupados el CM, aunque valora positivamente algunas de las medidas comunicadas por el Gobierno turco para evitar que se produzcan nuevas violaciones del CEDH por parte de sus fuerzas armadas, se pronuncia del siguiente modo: "[...] the CM note that the progress in redressing the violations has so far been slow and therefore urged the authorities to intensify their efforts to ensure that effective investigations are conducted in compliance with the Convention so that the responsable are held accountable» (Comité de Ministros, 2016: 133 y Comité de Ministros 2017: 140) ${ }^{56}$. Por último, y sin ánimo exhaustivo, cabe traer a colación Dink v. Turkey ${ }^{57}$, en el que se declara que Turquía ha vulnerado los arts. 2, 10, y 13 en relación con el primero, al no investigar efectivamente el asesinato de un periodista (Comité de Ministros, 2017: 103 y 139) $)^{58}$.

Por tanto, este sumario repaso de la práctica relativa a Turquía permite evidentes comparaciones con la estudiada respecto de la Federación de Rusia. En ambos supuestos se ponen de manifiesto las limitaciones que presenta el sistema de protección internacional de los derechos humanos establecido por el CEDH en situaciones en las que se producen vulneraciones graves y masivas de los derechos humanos, decididas o al menos toleradas por las propias autoridades civiles y/o militares del Estado. Por lo general no han colaborado en la ejecución de las sentencias que conlleve la investigación de los hechos y la sanción administrativa o penal de los principales responsables de tales vulneraciones. Sin perjuicio de que en algunos casos — no siempre— sí estén dispuestas a abonar alguna suma de dinero como satisfacción equitativa.

Lo que no impide que, en otros supuestos en los que no está en juego la vulneración de los derechos humanos inderogables, las autoridades turcas demuestren una mayor colaboración con el CM a la hora de ejecutar las sentencias dictadas en su contra. Por ejemplo, dentro de los principales casos

\footnotetext{
54 Sentencia de 25 de abril de 2006 (ECLI:CE:ECHR:2006:0425JUD001980792).

55 Sentencia de 20 de mayo de 2008 (ECLI:CE:ECHR:2008:0520JUD004590299).

56 https://bit.ly/2PkyQT8.

57 Sentenciade 14 deseptiembrede2010(ECLI:CE:ECHR:2010:0914JUD000266807).

58 https://bit.ly/2zWg52R.
} 
cerrados en 2016, destacan los 196 agrupados en torno a Demirel v. Turkey ${ }^{59}$ (Comité de Ministros, 2016: 154-155); eso sí, trece años después de dictarse la sentencia ${ }^{60}$.

\section{SOBERANÍA DE LOS ESTADOS Y DERECHOS HUMANOS EN EL ÁMBITO REGIONAL EUROPEO}

\section{VALORACIÓN DE LA PRÁCTICA ESTUDIADA}

Con carácter general, conviene poner de manifiesto que aunque en el seno del Consejo de Europa se ha puesto en práctica el más avanzado sistema de protección internacional de los derechos humanos en la historia de la humanidad, el establecido por el CEDH, el Consejo de Europa no deja de ser una organización internacional de ámbito regional europeo, formada como es obvio por Estados soberanos e independientes. Por tanto, que esta organización internacional pueda alcanzar los fines para los que fue creada, en gran medida depende de la efectiva aplicación del principio de cooperación entre sus Estados miembro y entre estos y los órganos que la estructuran, siempre en el contexto de un ordenamiento internacional esencialmente descentralizado (Carrillo Salcedo, 2001: 77-79 y 131-136). En esta dirección, y por lo que se refiere algo más en concreto a la problemática jurídico institucional que presenta la ejecución de las sentencias del TEDH, resulta comprensible que en el informe recientemente elaborado por el Comité Jurídico y derechos humanos de la AP se mantenga el siguiente el punto de partida: «The implementation of judgments depends above all on the political will of States» (Asamblea Parlamentaria, 2018: 40).

59 Sentencia de 28 de enero de 2003 (ECLI:CE:ECHR:2003:0128JUD003932498).

60 En los que estaba en juego la vulneración del art. 5 del CEDH por las condiciones de detención en las comisarías y cárceles turcas establecidas por la legislación de este país, con la que se permitía la prisión provisional durante nada menos que cinco años y no se preveía ningún mecanismo de indemnización en caso de que la detención hubiera sido declarada ilegal. A la vista de las medidas adoptadas por las autoridades turcas para evitar nuevas vulneraciones del art. 5 del $\mathrm{CEDH}$, entre otras disminuir a dos años el plazo máximo de la prisión provisional y el establecimiento de un procedimiento para obtener una indemnización en el supuesto de que la prisión provisional sea declarada ilegal, el CM decide dar por concluido el procedimiento de supervisión de la ejecución de este grupo de casos, mediante la Resolución CM/ ResDH(2016)332, de 9 de noviembre de 2016 (véase: https://bit.ly/2NqXfEN). 
En el ámbito de la protección de los derechos humanos, la efectiva aplicación del principio de cooperación por parte de las autoridades de todos los Estados miembro del Consejo de Europa se debe presumir, iuris et de iure, puesto que todos ellos se comprometen a respetar los derechos humanos de todas las personas que se hallen bajo su jurisdicción (art. 3 del Estatuto). Ya se ha insistido en que según su tratado constitutivo el respeto de los derechos humanos constituye una exigencia para la admisión de nuevos Estados miembros en esta OI, así como una condición para que un Estado miembro no sea suspendido en su derecho de representación o incluso expulsado (art. 8 del Estatuto). Por tanto, a tenor de las disposiciones de su tratado constitutivo, el Consejo de Europa debería ser una organización internacional formada por Estados con un alto nivel de homogeneidad por lo que se refiere al cumplimiento del citado art. 3 de su Estatuto.

Pero los supuestos de la Federación de Rusia y de Turquía - y también otros, como los de Azerbaiyán...- demuestran la evidente heterogeneidad política, económica, social... que presentan algunos de los Estados que forman parte de esta OI. Lo que, al menos por lo que respecta a estos dos Estados, repercute negativamente en el nivel de respeto de los derechos humanos que demuestran; tanto en el ámbito de sus respectivos internos, como en última instancia dentro del sistema de protección internacional de los derechos humanos establecido por el CEDH. Se han cumplido así los pronósticos que vaticinaban las dificultades que para este sistema de protección de los derechos humanos podía suponer la incorporación de Estados con sistemas democráticos muy poco consolidados. Como señalaba Carrillo Salcedo hace quince años (2003: 77), «el fuerte ritmo de aumento del número de Estados miembros ha traído consigo una creciente heterogeneidad que obliga a preguntarnos si estos nuevos Estados miembros (por ejemplo, la Federación de Rusia) están preparados para asumir las obligaciones que derivan del CEDH)».

Como se ha comprobado, el sistema no ofrece una respuesta efectiva ante buena parte de las vulneraciones graves y masivas de los derechos humanos que se han cometido en estos dos Estados durante las últimas décadas, muchas de ellas responsabilidad directa de las propias fuerzas de seguridad del Estado, siguiendo indicaciones o al menos con la indiferencia o la pasividad de las autoridades estatales (López Bofill, 2014: 104 y ss.). Sin que se deba despreciar, ni mucho menos, el hecho de que estos dos Estados formen parte del Consejo de Europa y estén sometidos a la competencia del TEDH, y, por tanto, los ordenamientos jurídicos y las autoridades legislativas, judiciales y gubernamentales de la Federación de Rusia y de Turquía se encuentren formalmente vinculadas y bajo la influencia del CEDH. Pero el estudio de la práctica pone de manifiesto que la apuesta que se hizo en su momento por «ayudar desde dentro» a los procesos de transición democrática en estos Estados, relativizando 
en elevado grado las condiciones de admisión y permanencia en el Consejo de Europa, está teniendo un alto coste por lo que se refiere a la efectiva aplicación del sistema de protección de los derechos humanos establecido por el CEDH (Salinas Alcega, 2009: 312).

En efecto, el estudio de la práctica permite llegar a la conclusión de que en cientos de casos que afectan a la vulneración de los derechos humanos más fundamentales, como la vida o la integridad física, la respuesta que ha ofrecido el sistema de protección regional europeo no ha sido capaz de asegurar la aplicación efectiva de las disposiciones infringidas. Después de agotar los recursos internos, los demandantes han tenido que esperar durante varios años para que el TEDH dictara sentencia; $y$, con posterioridad, las sentencias se han incumplido durante nada menos que una década o incluso en algunos casos sencillamente no se han cumplido, y tampoco se aprecian perspectivas de que vayan a cumplirse en un futuro más o menos cercano. Aunque en bastantes ocasiones - no siempre - las autoridades de estos dos Estados suelen hacer efectiva las cantidades económicas que en concepto de satisfacción equitativa - y de costas y gastos del proceso- establece el TEDH en sus sentencias, muchas más dificultades se plantean para que hagan efectiva tanto la obligación de restitutio in integrum como la obligación de dar satisfacción y/o garantías de no repetición de tales violaciones en el futuro.

Por tanto, por lo que respecta a la Federación de Rusia y a Turquía, hasta ahora en buena medida el CEDH no ha cumplido la función armonizadora en el ámbito del respeto de los derechos humanos que se debe predicar de este instrumento convencional ${ }^{61}$. Con lo que se está poniendo en peligro la propia existencia de un orden público europeo basado en los principios de democracia, Estado de derecho y respeto de los derechos humanos, siempre por lo que se refiere a estos dos Estados. En una perspectiva todavía más general, el somero estudio de la práctica que se ha realizado permite incluso poner en discusión si la actuación de las autoridades de estos dos Estados se puede valorar como de impugnadora de la existencia de un consensus $^{62}$ de ámbito regional

61 Como afirma el secretario general del Consejo de Europa en el prólogo al informe del Steering Committee for Human Rights $(2016,7)$ : «[el CEDH] not only does it provide a common ground between nations, based on agreed laws and shared values: by setting out the fundamental freedoms all in Europe must respect, the Convention is a source of cohesion in our increasingly diverse societies, too».

62 Entendido como «el conjunto de intereses y convicciones generales del grupo social internacional a los que se adhieren o aceptan los actores que lo forman, y que conduce necesariamente al cumplimiento probable de pautas habituales de comportamiento en el seno de dicho grupo» (Jiménez Piernas, 1994: 95). 
europeo sobre tales principios, tanto en el caso de la Federación de Rusia ${ }^{63}$ como en el de Turquía ${ }^{64}$.

63 Por lo que se refiere a la Federación de Rusia, es sabida la participación de sus tropas en conflictos que se producen no solo en su propio territorio - Chechenia-, sino también en antiguas repúblicas soviéticas —Ucrania, Georgia...- y otros terceros Estados - Siria-, en cuyo contexto se vienen cometiendo vulneraciones graves y masivas de los $\mathrm{DH}$ bajo su jurisdicción (art. $1 \mathrm{CEDH}$ ). Todo ello hace prever que en los próximos años se seguirán presentando miles de demandas contra este Estado en Estrasburgo. Se debe añadir que el 15 de diciembre de 2015 entraron en vigor reformas a ley que regula la Corte Constitucional en la Federación Rusa, según las cuales esta última tiene competencia, a solicitud del Gobierno ruso, para establecer si lo dispuesto en una sentencia o en una decisión de una instancia internacional, como el TEDH, es o no conforme con la Constitución de este Estado. De darse el segundo supuesto, la sentencia del TEDH deberá ser incumplida por las autoridades rusas (Laval, 2017: 679-682), en clara contravención con lo dispuesto en el art. 27 de la Convención de Viena sobre el Derecho de los Tratados, de 23 de mayo de 1969 (BOE, 13 de junio de 1980), y más en particular con lo preceptuado en el art. 46 del CEDH. Como así lo ha reconocido la Comisión Europea para la Democracia a través del Derecho (Comisión de Venecia) en su Opinión 832/2015, de 10-11 de junio de 2016 (párr. 42 y 143-145), disponible en: https://bit.ly/2Pk3M5Z. Pero el TC ruso ya ha dictado dos sentencias, la primera de 19 de abril de 2016, que declara inejecutable Anchugov and Gladkov v. Rusia, Sentencia de 4 de julio de 2013 (ECLI:CE:ECHR:2013:0704JUD001115704); y la segunda de 19 de enero de 2017, con la misma conclusión respecto de OAO Neftyanaya Kompaniya Yukos c. Rusia, Sentencia de 31 de julio de 2014 (ECLI:CE:ECHR:2011:0920JUD001490204) (objeto de comentario por parte de Timofeyev, 2017: 1-3). Se puede añadir, en esta interminable historia de desencuentros entre las autoridades rusas y los órganos del CoE, que a raíz de la invasión de la península de Crimea en 2014, la Asamblea Parlamentaria suspendió el derecho de voto de los representantes de la Federación de Rusia en la Asamblea Parlamentaria así como su participación como observadores en misiones electorales. Como respuesta, el Gobierno ruso ha amenazado con dejar de pagar su contribución anual, 33 millones de euros, al presupuesto de esta OI, que suma un total de 454 millones de euros. Además, las autoridades rusas se niegan reconocer la legitimidad del TEDH si no pueden participar en la votación que se lleva a cabo en la Asamblea Parlamentaria para su elección (véase: https://on.ft.com/2kK0N8Q).

Por lo que concierne a Turquía, es conocido el incumplimiento grave y masivo de los $\mathrm{DH}$ que protagonizan sus autoridades en el contexto de los conflictos que se vienen arrastrando desde hace décadas — invasión del norte de Chipre, Kurdistán turco...y también durante los últimos años en el marco de la intervención de su ejército en el conflicto sirio. Más recientemente, el Gobierno turco ha aprovechado el intento de golpe de Estado de 15 de julio de 2016 para decretar el estado de emergencia, todavía en vigor a fecha de hoy. Como consecuencia, se han derogado la mayor parte de los 
En este orden de cosas, se podrá decir, con razón, que las dificultades que presenta la ejecución de las sentencias del TEDH que conciernen a la Federación de Rusia y a Turquía también se pueden predicar respecto de las sentencias de otros tribunales internacionales, cuya ejecución asimismo descansa en la colaboración que se obtenga de las autoridades del Estado, en una perspectiva general en aplicación del principio de la buena fe como principio estructural del derecho internacional. Colaboración que se ha de concretar a la hora de que el Estado infractor cese y repare el hecho internacionalmente ilícito, a través de la restitutio in integrum, la indemnización y la satisfacción y las garantías de no repetición (Ben Mansour 2011: 226-248 y 326-447; Sudre, 2017: 923-934). Si se toma como referencia a su homólogo regional, sin duda la ejecución de las sentencias de la Corte Interamericana de Derechos Humanos (CIDH) necesita de la cooperación por parte de las autoridades de los Estados americanos, objeto de supervisión por la propia Corte. Como principal vía de presión sobre las autoridades del Estado declarado infractor, la $\mathrm{CIDH}$ puede denunciar públicamente los incumplimientos de sus sentencias en el informe anual que presenta a la Asamblea General de la OEA (Fortas, 2015: 12 y 540-563; Quispe Remón, 2016: 248-253). Los datos globales evidencian un balance muy pobre: de las 218 Sentencias dictadas por la CIDH entre 1988 y 2017 que declaran la vulneración de los DH, solamente 29 han sido íntegramente ejecutadas (Corte Interamericana de Derechos Humanos, 2017: 65 y ss.). Sin que la Asamblea General de la OEA haya tomado decisiones al respecto, más allá de aprobar Resoluciones en las que se recuerda genéricamente la obligación que corresponde a los Estados partes de cumplir las sentencias de la CIDH (González Morales, 2013: 150-155; Tigroudja, 2017: 684-686).

Pero el que se trate de un déficit que afecta en mayor o menor grado a otras instancias jurisdiccionales internacionales, no debe servir en absoluto de justificación para llevar a cabo una valoración complaciente o al menos en parte comprensiva ante las graves limitaciones que presenta el sistema europeo de protección internacional de los derechos humanos. Nada menos que en el ámbito de la ejecución de las sentencias del TEDH y en particular las referidas a la vulneración de los derechos humanos considerados inderogables por el CEDH. El estudio de la práctica relativo a la Federación de Rusia y a

derechos y libertades fundamentales; han sido detenidas unas 78000 personas, han sido apartados de sus puestos decenas de miles de funcionarios, jueces, maestros, profesores... Y se ha presentado una lluvia de demandas contra Turquía en Estrasburgo. Para un resumen reciente de la situación política y en materia de DH en Turquía, se puede consultar European Commission (2018: 8 y ss.). 
Turquía evidencia las carencias de gran envergadura que presenta el sistema de protección de los derechos humanos instaurado por el CEDH.

Se podrá señalar, también, que la mayor parte de las violaciones de los arts. 2 y 3 declaradas por el TEDH en cientos de sentencias pendientes de ejecutar por parte de la Federación Rusa y de Turquía se han cometido en el contexto de situaciones de conflicto interno, de mayor o menor intensidad —Chechenia, Kurdistán turco...- o incluso internacional —Chipre...-, y políticamente muy complejas; y que, por ende, la efectiva protección de los derechos humanos en tales situaciones necesita de una solución política al conflicto que constituye su caldo de cultivo. Aunque esta valoración general se pueda compartir, al mismo tiempo debe quedar bien claro que no es conforme con el CEDH que la Federación de Rusia o Turquía aleguen situaciones de conflicto interno o internacional para tratar de justificar la inejecución de sentencias del TEDH relativas a los arts. 2 y 3 del CEDH. Desde luego, el art. 15 de este tratado internacional no lo permite.

Pero en el seno del Consejo de Europa se viene insistiendo, como es comprensible, en la necesidad de dar solución a estos conflictos, como mejor receta para conseguir el cese y la reparación de las vulneraciones de los derechos humanos y prevenir nuevas violaciones. En este sentido se pronunciaba no hace mucho el Steering Committee for Human Rights en referencia a la labor de supervisión que corresponde al CM: «The implementation of some judgments is problematic for reasons of a more political nature. These are the cases related to serious large-scale violations committed in the context of complex problems that call for political solutions and peaceful settlement, or other cases where there is a lack of political will for their implementation» (Steering Committee for Human Rights, 2016: 74).

A este respecto, se ha defendido que el que recaiga sobre el CM la función de supervisión de la ejecución de las sentencias del TEDH es la mejor opción, dado que por la propia naturaleza de este órgano, es el que dispone de mayor capacidad de presión política para conseguir la colaboración de las autoridades estatales a la hora de que respeten los derechos humanos y estén dispuestas a dar cumplimiento a las sentencias del TEDH, incluso en situaciones de conflicto interno o internacional (Salinas Alcega, 2015: 9). Aunque cabría plantear que la supervisión de la ejecución de las sentencias fuera responsabilidad de otros órganos, como el propio TEDH, siguiendo el ejemplo que supone la mencionada labor de control de la ejecución de sus propias sentencias que lleva a cabo la CIDH. Con ello se evitaría que la supervisión de la ejecución de las sentencias se vea sometida a la discrecionalidad de la que puede hacer uso un órgano político como es el CM. Pero los Estados partes no apuestan por esta posible reforma del sistema; no hace mucho el Steering 
Committee for Human Rights manifestó su oposición por las siguientes razones:

It was recalled that the Committee of Ministers' supervision was an important reflection of collective enforcement within the Convention system and would be lost were responsibility transferred elsewhere. It was also noted that there would not necessarily be any saving in terms of resources, given that all other things being equal there would be the same number of judgments and decisions whose execution would need supervising. In addition, it was noted that the Committee of Ministers was by definition better placed to influence political entities and ensure adequate coordination with other Council of Europe instances and activities, and where necessary, the creation of different expert bodies" (Steering Committee for Human Rights, 2016: 86).

No obstante esta postura que pretende salvaguardar las prerrogativas que el vigente $\mathrm{CEDH}$ atribuye al CM, la conclusión general que se deriva del estudio de la práctica en los supuestos de la Federación de Rusia y de Turquía se puede resumir del siguiente modo: o bien el CM no dispone de mecanismos ni de instrumentos a través de los cuales pueda ejercer de forma efectiva su influencia y/o su presión sobre las autoridades de estos dos Estados para que cumplan su obligación de ejecutar las sentencias dictadas en su contra, más allá del debate inter pares que se desarrolla en su seno y de la publicidad que caracteriza en los últimos años al proceso de supervisión, como se ha insistido en el epígrafe II.2; o bien el CM no hace uso de los que tiene a su alcance por consideraciones de carácter político.

En efecto, como también se ha señalado - II.1-, hasta la fecha el CM no se ha decidido a expulsar al Estado, ni a suspender su derecho de representación, que incumpla la obligación de ejecutar las sentencias del TEDH. Los Estados miembro reunidos en el CM, al menos una mayoría de ellos, esgrimen que mientras estos Estados formen parte del Consejo de Europa, más capacidad de influencia se podrá desplegar desde los órganos de esta organización internacional para que se respeten los derechos humanos de las personas que se encuentren bajo su jurisdicción. Aunque como se ha comprobado en los supuestos de la Federación de Rusia y de Turquía (III y IV), de hecho la capacidad de influencia que el CM consigue a través del desarrollo del procedimiento de supervisión resulta más que relativa.

Asimismo, ya se ha reseñado que tras haberse cumplido ocho años desde su entrada en vigor, los preceptos introducidos por el Protocolo 14 que regulan los recursos de interpretación y por incumplimiento solamente han sido aplicados en una ocasión, en el citado Mammadov. A buen seguro por motivaciones de índole política, el CM ha optado por no aplicar estas disposiciones 
ni siquiera en casos en los que está en juego el cumplimiento de sentencias en las que se constata la vulneración grave y masiva de los derechos humanos inderogables por parte de la Federación de Rusia y de Turquía.

Tampoco parece que la instauración formal de estos dos recursos y la posibilidad de interponerlos por parte del CM, en especial el recurso por incumplimiento, haya tenido un efecto disuasorio apreciable sobre estos dos Estados, a los efectos de que sus autoridades demuestren una mayor colaboración con el CM para el cumplimiento de su obligación de ejecutar las sentencias dictadas en su contra. En el informe explicativo del Protocolo 14 se defendía que no se había incluido la posibilidad de que a través del recurso por incumplimiento el TEDH pudiera aplicar una sanción económica, ya que se consideraba que «la pression politique que constituerait un tel recours en manquement devant la Grande Chambre et l'arrêt de celle-ci devraient ètre suffisants pour que l'Etat concerné exécute l'arrêt initial de la Cour». Después de prever su aplicación solo en situaciones excepcionales, en ese mismo informe se señalaba que "la simple existence d'une telle procédure de recours en manquement et la menace d'y avoir recours devraient avoir un nouvel effet incitatif efficace quant à l'exécution des arrêts de la Cour» ${ }^{65}$. No parece que estas previsiones se hayan cumplido: como se ha comprobado, tanto la Federación de Rusia como Turquía presentan un muy deficiente balance por lo que respecta al cumplimiento de las sentencias del TEDH; y nada indica que el posible efecto disuasorio que se podría derivar de la mera existencia del recurso por incumplimiento haya influido decisivamente para que las autoridades de estos dos Estados corrijan o al menos mejoren sustancialmente el deplorable registro que vienen protagonizando en este ámbito.

Hasta la fecha solamente se ha hecho uso una vez del art. 46.4, y todo apunta a que en el futuro la interposición de estos dos recursos, y en especial el recurso por incumplimiento, se va a aplicar con cuentagotas. En esta dirección se manifestaban los Estados partes en el CEDH, de forma un tanto ambigua, en la Declaración de Copenhague aprobada en la Conferencia Interministerial celebrada los días 12 y 13 de abril de 2018, en la que se puede leer lo siguiente: «Strongly encourages the Committee of Ministers to continue to use all the tolls at its disposal when performing the important task of supervising the execution of judgments, including the procedures under Article 46 (3) and (4) of the Convention keeping in mind that it was foreseen that they would be used sparingly and in exceptional circumstances respectively» (párr. 24) ${ }^{66}$.

65 Párrs. 99-100: https://bit.ly/2C66GYi.

66 Véase: https://bit.ly/2Cylopq. 
Falta por ver respecto a qué casos el CM va a apreciar en el futuro que se dan esas circunstancias excepcionales que justifiquen la interposición del recurso por incumplimiento. A fecha de hoy, tras haber transcurrido ocho años desde la entrada en vigor del Protocolo 14, el CM no ha considerado que se dieran tales circunstancias en ningún caso referido a la Federación de Rusia y a Turquía, Estados ambos que acumulan más de un millar de sentencias pendientes de ejecutar, entre las que destacan centenares de ellas que declaran la vulneración de los arts. 2 y 3 del CEDH. Por tanto, los propios Estados partes consideran que el recurso por incumplimiento casi nunca se va a aplicar. Además, como se va a insistir a continuación, en los casos en los que se interponga el TEDH únicamente va a poder declarar el incumplimiento de su propia sentencia sin ninguna otra consecuencia concreta para el Estado infractor. Por todo ello, con tales condiciones resulta casi inverosímil que se pueda dar el efecto disuasorio que se predicaba de la simple regulación de la posibilidad de interponer este recurso. El estudio de la práctica en los casos de la Federación de Rusia y de Turquía así lo confirma.

Se puede traer a colación a este respecto que, como es sabido, se han presentado muy pocas demandas interestatales ante el TEDH, de conformidad con el art. 33 del $\mathrm{CEDH}^{67}$. Lo que demuestra las reticencias que suelen mantener los Gobiernos de los Estados a la hora de denunciarse entre sí a causa de la vulneración de los derechos humanos. Por la misma regla de tres, no va a ser nada frecuente que de forma colectiva, en el seno del CM, una mayoría muy cualificada de Estados partes en el CEDH - dos terceras partes o lo que es lo mismo, 31 de los 47 Estados partes en el CEDH - consiga acordar la interposición del recurso por incumplimiento en aplicación del art. 46.4. Más aún si se tiene en cuenta que buena parte de los Estados acumulan sentencias del TEDH pendientes de ejecutar (De Londras y Dzehtsiarou, 2017: 482-483) ${ }^{68}$.

En esta misma dirección, tampoco se ha hecho efectiva hasta hoy la posibilidad de que se presente una demanda interestatal en virtud del art. 33 del

67 La lista de sentencias dictadas hasta la fecha por el TEDH en respuesta a demandas interestatales (por Austria contra Italia; Irlanda contra Reino Unido; Francia, Noruega, Dinamarca, Suecia y Holanda contra Turquía; Chipre contra Turquía, y Georgia contra la Federación de Rusia) se puede consultar en: https://bit.ly/2Remht4.

68 Por ejemplo, incluso Estados con una larga tradición democrática, como Italia (como se ha señalado anteriormente) o como el Reino Unido, cuyas autoridades hasta la fecha no han ejecutado las sentencias del TEDH en las que se declara que este Estado incumple el art. 3 del Protocolo 1 del CEDH al no permitir a los presos el ejercicio del derecho de sufragio; entre otras, en Hirst v. United Kingdom (N. $\left.{ }^{\circ} 2\right)$, Sentencia de la Gran Sala de 6 de octubre de 2005 (ECLI:CE:ECHR:2005:1006JUD007402501) (véase: https://bit.ly/2RAcAWH). 
CEDH contra un Estado que incumpla el art. 46.1 al no ejecutar una sentencia dictada en su contra por el TEDH. Esta vía de recurso podría considerarse abierta a la vista del amplio campo de aplicación con el que se contempla el recurso interestatal en el citado art. 33, ya que puede ser relativo a «cualquier incumplimiento de lo dispuesto en el Convenio y sus Protocolos que, [...] pueda ser imputado a otra Parte Contratante» (Salinas Alcega, 2009: 206207). No obstante, cabe poner muy en duda su virtualidad si se tiene en cuenta la doctrina que mantiene el TEDH a la hora de declararse incompetente para conocer de demandas relativas exclusivamente al incumplimiento del art. 46.1, en orden a salvaguardar las prerrogativas que a este respecto prevé el art. 46.2 en favor del CM, como el Tribunal de Estrasburgo puso de manifiesto con rotundidad en Moreira Ferreira v. Portugal (N.o 2), citado supra en II.2.

\section{ALGUNAS PROPUESTAS DE LEGE FERENDA}

Ante el deficiente balance que presenta el sistema de protección en este ámbito, cabe plantear algunas propuestas de lege ferenda, que deberían ser plasmadas en el CEDH y/o en las citadas Normas de Ejecución. En primer lugar, cabe demandar que el CM haga uso del recurso por incumplimiento contra Estados reacios al cumplimiento de las sentencias del TEDH. No hace mucho, la Asamblea Parlamentaria aprobaba una recomendación titulada «The Implementation of Judgments of the European Court of Human Rights», en la que entre otras recomendaciones dirigidas al CM, así se lo solicitaba con carácter general ${ }^{69}$.

Desde la perspectiva de la efectiva aplicación de los derechos humanos protegidos por el CEDH, no es de recibo que tras agotar los recursos internos, $y$ tras esperar varios años a que el TEDH dicte sentencia, el demandante se

69 Recomendación 2110 (2017), aprobada el 29 de junio de 2017. Además de las siguientes recomendaciones: que el CM haga uso con mayor frecuencia de las resoluciones provisionales para establecer las dificultades que plantea la ejecución de determinadas sentencias; que tenga en cuenta urgentemente los problemas sistémicos identificados en sentencias piloto del TEDH, con atención a todos los casos relacionados; que se garantice una mayor transparencia en el proceso de supervisión; que se le dé a los demandantes, sociedad civil y a los órganos nacionales dedicados a la protección de los derechos humanos «a greater role in this process»; que se desarrollen sinergias entre todos los participantes en el proceso de ejecución; que se incrementen los recursos del Servicio de Ejecución; que se incrementen los intercambios entre el Servicio de Ejecución y el TEDH y el Registro, y las consultas con las autoridades nacionales. Véase: http://assembly.coe.int/nw/xml/XRef/Xref-DocDetails-EN.asp?FileID=23988\&lang=2. 
encuentre con que la sentencia tarda un buen número de años en ejecutarse, sin que desde el CM se adopte medida alguna, más allá de aprobar alguna resolución provisional. Por ello, cabe proponer que cuando las circunstancias del caso así lo justifiquen en orden a garantizar la efectiva aplicación de los derechos humanos reconocidos por el CEDH, y en todo caso siempre por lo que respecta a las sentencias piloto y aquellas sentencias que contengan indicaciones relevantes para su ejecución, el TEDH debería establecer un plazo para que el Estado declarado infractor cumpla la sentencia que se ha dictado en su contra, y abone la satisfacción equitativa y adopte las medidas individuales y generales determinadas por este órgano judicial. Transcurrido ese plazo, si el CM considerara, a propuesta del Servicio de Ejecución ${ }^{70}$, que el Estado no ha ejecutado la sentencia, automáticamente debería presentar un recurso por incumplimiento ante el TEDH. Salvo que por circunstancias excepcionales, que debería alegar y acreditar el Estado concernido, el CM, por una mayoría de dos tercios de sus miembros, decidiera prorrogar anualmente el plazo establecido por el TEDH.

En este mismo sentido, si en su sentencia el TEDH no indicara ningún límite de tiempo para su cumplimiento, se debería establecer un plazo general máximo de dos años desde que la sentencia es definitiva. Finalizado este plazo, si el CM considera, siempre a propuesta de su Servicio de Ejecución, que el Estado no ha ejecutado la sentencia, debería interponer también automáticamente el recurso por incumplimiento: ya sea respecto de todas las sentencias del TEDH cualquiera que sea el precepto del CEDH vulnerado, ya sea al menos por lo que se refiere a las sentencias relativas a la vulneración de los derechos humanos considerados inderogables por el art. 15 del CEDH, así como también en el supuesto de la vulneración del art. 5. De nuevo salvo que por circunstancias excepcionales que debería alegar y acreditar el Estado concernido, el CM, por una mayoría de dos tercios de sus miembros, decidiera prorrogar anualmente ese plazo de dos años.

También de lege ferenda cabe proponer que a la hora de responder a los recursos por incumplimiento que se le presenten, el TEDH debería tener

70 A este respecto, se deberían incrementar los recursos humanos y financieros del Servicio de Ejecución, como se propone en la citada recomendación de la Asamblea Parlamentaria, para que pueda asistir diligentemente al CM en su labor de supervisión de la ejecución de miles de casos pendientes. El Steering Committee for Human Rights (2016: 89) también pide que se asegure que el Servicio de Ejecución va a disponer de suficientes recursos, materiales y humanos, y más en concreto propone que al menos debería contar con un jurista de cada uno de los Estados miembros, para asegurar así un buen conocimiento del ordenamiento jurídico interno de cada uno de los 47 Estados partes. 
competencia para imponer al Estado que no ejecuta la sentencia el pago de una suma a tanto alzado o de una multa coercitiva, con el objetivo de compelerle a ejecutar la sentencia. En aplicación de la terminología de la que se hace uso en el art. 260 TFUE, en el que se regula el recurso por incumplimiento en el ámbito del DUE (Ben Mansour, 2011: 447-452; Sudre, 2017: 923). La suma de dinero así determinada por el TEDH debería ser destinada en parte a los demandantes para cubrir la satisfacción equitativa - y las costas y gastosprevista en la sentencia del TEDH; en parte a financiar proyectos relacionados con la promoción y protección de los derechos humanos en el Estado en cuestión llevados a cabo desde la sociedad civil (ONG, asociaciones...). Porque tal y como está regulado el recurso por incumplimiento en el vigente art. 46.4, en su respuesta el TEDH se va a limitar a declarar que el Estado no ha ejecutado la sentencia dictada anteriormente, como ya sostiene el CM, sin ninguna otra consecuencia concreta. Por tanto, salvo que esta nueva sentencia por parte del TEDH se pueda valorar como una «sanción» política o moral contra el Estado ${ }^{71}$, es muy probable que con la puesta en práctica del recurso por incumplimiento se consuman tiempo y recursos por parte del TEDH de su Gran Sala - de los que desde luego no está sobrado, para ofrecer una conclusión a la que el CM ya había llegado. Está por ver si con esta regulación el recurso por incumplimiento puede contribuir a que los Estados cumplan con su obligación de ejecutar las sentencias dictadas por el TEDH (De Londras y Dzehtsiarou, 2017: 484-486).

Además, y en este mismo sentido y con carácter preventivo, los Estados partes que hayan sido objeto de un recurso por incumplimiento, deberían estar obligados a constituir un depósito u ofrecer un aval bancario que garantizara el pago inmediato de la suma a tanto alzado o la multa coercitiva, tras haberse dictado la sentencia que da respuesta al recurso por incumplimiento. Desde luego, sería el colmo de la falta de efectividad del sistema que después de agotar los recursos internos, esperar pacientemente a que el TEDH dicte sentencia y soportar varios años la inejecución de la misma, el demandante se encontrara con que el Estado demandado tampoco abona la suma a tanto alzado o la multa coercitiva resultado del recurso por incumplimiento. Sobre

71 Se podría valorar también que con el fallo que dicte el TEDH en aplicación del art. 46.4, la controversia sobre la protección de los derechos humanos de los demandantes que origina la sentencia que el Estado no ejecuta se convierte en una cuestión de responsabilidad internacional que concierne al Estado parte frente al resto de Estados partes en la Convención representados en el CM, en concreto por el incumplimiento del art. 46.1 del CEDH. En todo caso, falta por ver qué medidas aplicará el CM para hacer efectiva esa relación de responsabilidad internacional: ¿̨hará uso de las previsiones contempladas en el citado art. 8 del Estatuto del Consejo de Europa? 
todo, es previsible que con estas condiciones la mera posibilidad de interponer un recurso por incumplimiento por parte del CM sí podría tener el efecto disuasorio al que se refería el mencionado informe explicativo al Protocolo 14.

Asimismo, cabe formular otras propuestas de lege ferenda, dirigidas a asegurar al menos financieramente la ejecución de la sentencia. En este sentido, los Estados partes deberían acordar, a través de un protocolo a la CEDH, la obligación de regular en sus ordenamientos internos lo que se podría denominar jurisdicción civil universal — de ámbito europeo, eso sí-, y que no cabría alegar la inmunidad de jurisdicción, con relación a las demandas civiles que se presenten contra Estados partes que no ejecuten las sentencias dictadas en su contra por el TEDH, ante los tribunales internos de otros Estados partes, con el objetivo de obtener una indemnización económica que cubra la satisfacción equitativa y los gastos y costas del procedimiento. Y siempre dentro del cumplimiento de las normas del DI que regulan la inmunidad de ejecución de los Estados extranjeros ante los tribunales del Estado del foro (Ferrer Lloret, 2007: 59-60) $)^{72}$.

Falta por ver si todas o algunas de estas propuestas podrán ser consensuadas por los 47 Estados partes en el CEDH. A fecha de hoy, parece muy poco probable. De hecho, en los últimos años en el seno del Steering Committee for Human Rights se ha discutido la posibilidad de que el TEDH pueda imponer una sanción pecuniaria al Estado que incumpla una de sus sentencias; y la mayoría de los miembros se manifiestan en contra (Steering Committee for Human Rights, 2016: 86). Además, conviene añadir que una mayoría de los representantes en dicho comité (ibid:: 76) defiende que los Estados deben tener libertad para elegir los medios que estén a su disposición para cumplir las sentencias del TEDH, siempre que tales medios sean conformes con lo

72 Es cierto que en Naït-Liman v. Switzerland, sentencia de la Gran Sala de 15 de marzo de 2018 (ECLI:CE:ECHR:2018:0315JUD005135707), el TEDH mantiene que la decisión de los tribunales suizos de considerarse no competentes ante una demanda civil presentada por un nacional tunecino contra miembros del Gobierno de Túnez, por actos de torturas cometidos contra él en territorio del Estado norteafricano, no vulnera el art. 6.1 de la CEDH, ya que en opinión del TEDH el derecho internacional no impone la obligación a los Estados de establecer la jurisdicción civil universal en casos de tortura. Pero esta decisión del TEDH en la que valora el DI en vigor, no debería servir de obstáculo para que los Estados europeos adopten un protocolo a la $\mathrm{CEDH}$ con el contenido que se acaba de señalar, como DI particular o regional de ámbito europeo y en el marco del respeto de las normas que regulan la inmunidad de ejecución incluidas en la Convención de las Naciones Unidas sobre las Inmunidades Jurisdiccionales de los Estados y de sus Bienes, adoptada, por consenso, por la Asamblea General mediante la Resolución 59/38 de 2 de diciembre de 2004. 
dispuesto en las conclusiones del fallo. Pero al margen de casos excepcionales, en los que la naturaleza de la vulneración no deje margen de opción, el Steering Committee for Human Rights se muestra contrario a que el TEDH indique qué tipo de medidas individuales o generales debe adoptar el Estado para poner fin a la vulneración del CEDH. Según la opinión mayoritaria, «[...] the essential role of the court is to determine whether or not protected rights and freedoms have been violated and, where necessary, to decide on just satisfaction. States are then free to choose the means by which to give effect to the Court's judgments, subject to the supervision of the Committee of Ministers, in accordance with the principle of subsidiarity» (ibid:: 77-78) ${ }^{73}$.

Por tanto, una mayoría de los Gobiernos de los Estados partes prefieren, bajo la apariencia de la aplicación del principio de subsidiariedad — cuya aplicación además pretenden reforzar con la adopción del citado Protocolo 15-, seguir disfrutando de un amplio margen de discrecionalidad en el cumplimiento de las sentencias del TEDH, en el marco de la colaboración que a este respecto deben mantener con un órgano político, como es el CM, del que a su vez forman parte. Como se acaba de comprobar (III y IV), el CM viene protagonizando una actuación muy lenta y se podría decir que bajo mínimos a la hora de desarrollar el procedimiento de supervisión de la ejecución de buena parte de las sentencias del TEDH en los supuestos de la Federación de Rusia y de Turquía. Sentencias que permanecen inejecutadas durante periodos de tiempo muy prolongados, sin ninguna reacción por parte del CM, excepto por lo que se refiere a la publicación de algunas resoluciones provisionales.

Por consiguiente, todo apunta a que va a ser muy difícil que se alcance un consenso entre los 47 Estados partes que permita adoptar reformas en el $\mathrm{CEDH}$ relativas a la ejecución de las sentencias. Por ello, cabe propugnar que sean los veintiocho Estados miembros de la UE, o al menos una amplia

73 En esta misma dirección, y con relación a la reapertura de procedimientos judiciales como consecuencia de la ejecución de las sentencias del TEDH, para el Steering Committee for Human Rights «this is only one of the means to secure to the applicant restitutio in integrum» (2016: 88). Por lo que respecta a la satisfacción equitativa prevista en el art. 41 del CEDH, cuando la vulneración de los derechos humanos no puede ser reparada a través del derecho interno del Estado parte, el Comité critica que «in practice, however, the Court often awards just satisfaction without having explored the question of whether or not the relevant national law allows for only partial reparation». Lo que conduce a que muchos demandantes conciban al TEDH como una especie de tribunal de compensación o tribunal de cuarta instancia. Por lo que se solicita que "the criteria applied by the Court when applying Article 41 of the Convention become more transparent and take into account national economic circumstances» (ibid.: 78). 
mayoría ${ }^{74}$, junto con otros Estados — Noruega...- los que defiendan la elaboración de un protocolo en el que se incluyan todas o al menos alguna de estas propuestas. Protocolo que siguiendo el ejemplo del citado Protocolo 16, entraría en vigor cuando se reunieran solamente diez ratificaciones, y por supuesto no vincularía a los Estados partes en el CEDH que no lo ratificaran. Quizás esta alternativa podría permitir algunos avances en el ámbito de la ejecución de las sentencias del TEDH, que eso sí de entrada solo se aplicarían a los Estados partes que ratifiquen tales cambios normativos. Y habría que confiar en que con el paso del tiempo se fueran incorporando otros Estados partes en el CEDH. Porque a fecha de hoy, esperar que las autoridades de Estados como la Federación de Rusia o Turquía estén dispuestas a aceptar estas propuestas resulta muy poco realista.

\section{CONCLUSIONES}

La impresionante sobrecarga de trabajo a la que está sometido el sistema de protección de los derechos humanos establecido por el CEDH también se proyecta con toda claridad en el ámbito de la ejecución de las sentencias del $\mathrm{TEDH}$, responsabilidad de un órgano de composición intergubernamental como es el CM. Aunque los datos de las últimas anualidades ponen de manifiesto un balance positivo por lo que se refiere a la aminoración del número de casos pendientes de ejecutar, el sistema se ve en buena medida desbordado ante la existencia de una bolsa de miles de sentencias del TEDH que todavía no se han ejecutado.

El CM viene aplicando, con la ayuda del Servicio de Ejecución, un procedimiento de supervisión de la ejecución de las sentencias del TEDH basado en el diálogo y la cooperación con las autoridades del Estado declarado infractor. Como se concreta formalmente a través de los planes y balances de acción presentados por el Estado, y las resoluciones provisionales y finales adoptadas por el CM. En este sentido, la efectividad del procedimiento de supervisión esencialmente descansa en la colaboración que se obtenga de las autoridades

74 Si se tiene en cuenta la deriva de corte autoritario que durante los últimos años mantienen las autoridades de algunos de los Estados miembros de la UE, como Polonia o Hungría, en temas tan fundamentales para la existencia de un Estado de derecho y el respeto de los derechos fundamentales, como la independencia del poder judicial (Mangas Martín, 2018: 5 y ss.), resulta muy aventurado esperar que los Gobiernos de los mencionados Estados vayan a ser partidarios de reformas en el sistema de protección establecido por el CEDH dirigidas a garantizar la efectividad de las disposiciones de este Convenio. 
estatales; si bien, pueden verse sometidas a la presión política que se derive del desarrollo del procedimiento de supervisión en el seno del CM y de la publicidad de toda la información referida al mismo. Pero hasta la fecha el CM solo ha interpuesto en una ocasión el recurso por incumplimiento previsto en el art. 46.4 del CEDH, en Mammadov v. Azerbaijan; y en ningún caso el recurso de interpretación contemplado en el art. 46.3. Tampoco se ha expulsado a ningún Estado del Consejo de Europa, ni se ha suspendido su derecho de representación, como consecuencia del incumplimiento de su obligación de ejecutar las sentencias definitivas del TEDH.

Ni siquiera en supuestos como los de la Federación de Rusia y de Turquía, Estados ambos que acumulan cientos de sentencias sin ejecutar en las que se declara la vulneración de derechos humanos inderogables, como el derecho a la vida o el derecho a la integridad física. Respecto de estos dos Estados, el CM viene protagonizando una actuación muy lenta y bajo mínimos, sin apenas reacción por su parte, excepto por lo que se refiere a la publicación de algunas resoluciones provisionales. Por tanto, por lo que respecta a la Federación de Rusia y a Turquía, hasta ahora el CEDH en buena medida no ha cumplido la función armonizadora en el ámbito del respeto de los derechos humanos que se debe predicar de este instrumento convencional. Incluso cabe poner en discusión si la actuación de las autoridades de estos dos Estados afecta o no a la existencia de un consensus de ámbito regional europeo sobre la vigencia del principio de respeto de los derechos humanos.

Ante esta situación cabe plantear algunas propuestas de lege ferenda. En primer lugar, el propio TEDH debería establecer en sus sentencias un plazo para su ejecución, al menos respecto de las sentencias piloto y otras sentencias que contengan indicaciones relevantes para su ejecución. Como alternativa, debería establecerse un plazo general de dos años para que el Estado ejecutara la sentencia. Transcurrido uno u otro plazo, el CM debería interponer automáticamente el recurso por incumplimiento ante el TEDH, salvo que circunstancias excepcionales justificaran su prórroga anual. Asimismo, cuando el CM interponga un recurso por incumplimiento, el TEDH debería estar facultado para imponer una suma a tanto alzado o una multa coercitiva sobre el Estado que no ejecuta la sentencia. Además, los Estados que sean objeto de dicho recurso deberían estar obligados a constituir un depósito u ofrecer un aval bancario que garantizara el pago de la suma a tanto alzado o multa coercitiva, una vez el TEDH dé su respuesta al recurso por incumplimiento. También se puede defender que se instaure la jurisdicción civil universal de ámbito regional europeo ante los tribunales de cualquier Estado, y que no cabe alegar la inmunidad de jurisdicción, con relación a las demandas civiles que se presenten contra Estados partes que no ejecuten las sentencias dictadas por el TEDH. 
Falta por ver si estas propuestas - y otras, como el muy necesario incremento de los recursos humanos y materiales del Servicio de Ejecución-, van a ser aceptadas por los 47 Estados partes en la CEDH. A fecha de hoy no parece nada previsible. Porque en última instancia, la eficacia del sistema de protección, por lo que se refiere a la ejecución de las sentencias del TEDH, se ve fuertemente condicionada por la tensión o contradicción de alcance general que emerge en el funcionamiento de los órganos del Consejo de Europa: entre, por una parte, la soberanía de los Estados miembros, concretada en la vigencia de los principios de cooperación en el ámbito general de esta organización internacional y de subsidiariedad en el ámbito más específico de la puesta en práctica del mecanismo de protección; y, por otra, el principio de respeto de los derechos humanos al que se comprometen los Estados partes en el CEDH y, más en particular, la obligación que asumen de ejecutar las sentencias que dicta el TEDH. La práctica estudiada sobre este sistema de protección de los derechos humanos en referencia a la Federación de Rusia y a Turquía evidencia los hasta ahora insalvables obstáculos que impiden la formación y consolidación del principio de solidaridad, sobre el que debería descansar la existencia de una estructura comunitaria en el ordenamiento internacional, todavía en estado muy embrionario, incluso en el ámbito regional europeo y por supuesto también en otros ámbitos regionales, como el establecido por la OEA.

Desde esta perspectiva, las reformas propuestas vendrían a constituir desarrollos más bien propios de una organización internacional de integración, y no de una basada fundamentalmente en el principio de cooperación, como es el Consejo de Europa. Por ello, como alternativa algo más viable, cabe propugnar que sea una mayoría de los veintiocho Estados miembros de la UE, junto con otros Estados, la que trate de poner en práctica estas propuestas, a través del correspondiente protocolo. Y habrá que esperar a que, si las circunstancias políticas, económicas, sociales... así lo favorecen, con el paso de los años otros Estados se vayan sumando a este esfuerzo dirigido a avanzar en el proceso de armonización jurídica basado en el principio del respeto de los derechos humanos establecido por el CEDH. Proceso que debe cimentarse, como no pude ser de otro modo, en la existencia de un alto grado de homogeneidad entre los Estados que participan.

\section{Bibliografía}

Abrisketa Uriarte, J. (2013). Las sentencias piloto: el Tribunal Europeo de Derechos Humanos, de juez a legislador. Revista Española de Derecho Internacional, 65 (1), 73-99. 
Asamblea Parlamentaria. (2018). The Implementation of Judgments of the European Court of Human Rights. Estrasburgo: Council of Europe.

Ben Mansour, A. (2011). La mise en oeuvre des arrêts et sentences des juridictions internationales. Bruxelles: Larcier.

Bowring, B. (2010). The Russian Federation, Protocol No. 14 (and 14bis), and the Battle for the Soul of the ECHR. Goettingen Jounal of International Law, 2, 589-617.

Carrillo Salcedo, J. A. (2001). Soberanía de los Estados y derechos humanos en derecho internacional contemporáneo. Madrid: Tecnos.

— (2003). El Convenio Europeo de Derechos Humanos. Madrid: Tecnos.

Comité de Ministros. (2016). Supervision of the Execution of Judgments and Decisions of the European Court of Human Rights 2016. 10 $0^{\text {th }}$ Annual Report. Estraburgo: Council of Europe. Disponible en: https://bit.ly/2zPHsvH.

(2017). Supervision of the Execution of Judgments and Decisions of the European Court of Human Rights 2017. $11^{\text {th }}$ Annual Report. Estraburgo: Council of Europe. Disponible en: https://bit.ly/2zPHsvH.

Corte Interamericana de Derecho Humanos. (2017). Informe Anual 2017. San José: Corte Interamericana de Derecho Humanos. Disponible en: https://bit.ly/ 2zOeJY0.

De Londras, F. y Dzehtsiarou, K. (2017). Mission Impossible? Addressing Non-Execution through Infringement Proceedings in the European Court of Human Rights. International and Comparative Law Quarterly, 66 (2), 467-490. Disponible en: https://doi.org/10.1017/S002058931700001X.

European Commission. (2018). Turkey 2018 Report. Strasburg: European Commission. Disponible en: https://bit.ly/2HaRBZ6.

Ferrer Lloret, J. (2007). La inmunidad de jurisdicción del Estado ante violaciones graves de los derechos humanos. Revista Española de Derecho Internacional, 59 (1), 29-64.

Fortas, A. C. (2015). La surveillance de l'exécution des arrêts et decisions des Cours Européenne et Interaméricaine des Droits de l'Homme. Contribution à l'etude du droit du contentieux international. Paris: Pedone.

González Morales, F. (2013). Sistema Interamericano de Derechos Humanos. Valencia: Tirant Lo Blanch.

Jiménez Piernas, C. (1994). El concepto de Derecho Internacional Público (II). En M. Díez de Velasco (ed.). Instituciones de Derecho Internacional Público (pp. 89113). Madrid: Tecnos.

Laval, P. F. (2017). Les limites constitutionnelles à l'exécution des arrêts de la Cour européenne des droits de l'homme à la lumière de la jurisprudence nationale comparée. Revue generale de droit international public, 121 (3), 661-682.

López Bofill, H. (2014). El Convenio Europeo de DH ante violaciones masivas de derechos. Revista Española de Derecho Europeo, 49, 91-124.

Mangas Martín, A. (2018). Polonia en el punto de mira: ¿solo riesgo de violación grave del Estado de Derecho? Revista General de Derecho Europeo, 44, 1-12. 
Morte Gómez, C. (2011). Eficacia de las sentencias del TEDH. Cursos de DH de Donostia-San Sebastián, 11, 225-242.

Quispe Remón, F. (2016). La protección de los derechos humanos en el sistema interamericano: su evolución y una visión actual. Anuario Español de Derecho Internacional, 32, 225-258. Disponible en: https://doi.org/10.15581/010.32.225258.

Saavedra Alessandri, P. y Cano Palomares, G. (2017). Reparación y supervisión de sentencias. En J. García Roca y E. Carmona Cuenca (eds.). ¿Hacia una globalización de los derechos? El impacto de las sentencias del Tribunal Europeo y de la Corte Interamericana (pp. 211-268). Navarra: Aranzadi.

Salinas Alcega, S. (2009). El sistema europeo de protección de los derechos humanos en el siglo XXI. El proceso de reforma para asegurar su eficacia a largo plazo. Madrid: Iustel.

(2015). El nuevo procedimiento de control de la ejecución de la sentencias del Tribunal Europeo de Derechos Humanos tras el proceso de Interlaken: la evolución técnica de un mecanismo político. Revista General de Derecho Europeo, 36, $1-42$.

Steering Committee for Human Rights. (2016). The longer-term future of the system of the European Convention on Human Rights. Strasburg: Council of Europe. Disponible en: https://bit.ly/2IAzSYC.

Sudre, F. (dir.). (2017). Les grands arrêts de la Cour européenne des Droits de l'Homme. Paris: PUF.

Tigroudja, H. (2017). L'obligation d'exécution dans le système interaméricain des droits de l'homme: vers l'affirmation d'un droit subjectif international à l'exécution des décisions de la Cour interaméricaine? Revue generale de droit international public, 121 (3), 683-688.

Timofeyev, M. (2017). Money makes the Court Go Round: The Russian Constitutional Court's Yukos Judgment. Disponible en: https://bit.ly/2zOnRMa. 